Atmos. Chem. Phys., 14, 3945-3968, 2014

www.atmos-chem-phys.net/14/3945/2014/

doi:10.5194/acp-14-3945-2014

(c) Author(s) 2014. CC Attribution 3.0 License.

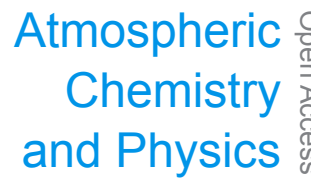

\title{
Long-term changes in the upper stratospheric ozone at Syowa, Antarctica
}

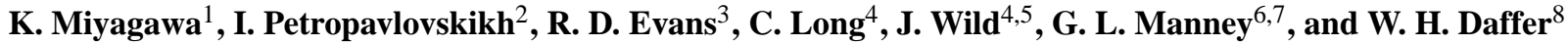 \\ ${ }^{1}$ Japan Meteorological Agency, Aerological Observatory, Tsukuba, Ibaraki, 305-0052, Japan \\ ${ }^{2}$ Cooperative Institute for Research in Environmental Sciences, University of Colorado, Boulder Colorado, USA \\ ${ }^{3}$ NOAA/OAR/ESRL Climate Monitoring Division, 325 Broadway, Boulder, Colorado, USA \\ ${ }^{4}$ NOAA/NWS/NCEP/Climate Prediction Center, College Park, MD, USA \\ ${ }^{5}$ Wyle ST\&E, Houston, TX, USA \\ ${ }^{6}$ NorthWest Research Associates, Socorro, NM, USA \\ ${ }^{7}$ New Mexico Institute of Mining and Technology, Socorro, NM, USA \\ ${ }^{8}$ Jet Propulsion Laboratory, California Institute of Technology, Pasadena, CA, USA
}

Correspondence to: K. Miyagawa (koji.miyagawa@gmail.com)

Received: 9 November 2012 - Published in Atmos. Chem. Phys. Discuss.: 7 January 2013

Revised: 12 February 2014 - Accepted: 28 February 2014 - Published: 17 April 2014

\begin{abstract}
Analyses of stratospheric ozone data determined from Dobson-Umkehr measurements since 1977 at the Syowa $\left(69.0^{\circ} \mathrm{S}, 39.6^{\circ} \mathrm{E}\right)$, Antarctica, station show a significant decrease in ozone at altitudes higher than that of the $4 \mathrm{hPa}$ pressure level during the 1980s and 1990s. Ozone values over Syowa have remained low since 2001. The time series of upper stratospheric ozone from the homogenized NOAA SBUV (Solar Backscatter Ultraviolet Instrument $)(/ 2) 8.6$ overpass data $\left( \pm 4^{\circ}, 24 \mathrm{~h}\right)$ are in qualitative agreement with those from the Syowa station data. Ozone recovery during the austral spring over the Syowa station appears to be slower than predicted by the equivalent effective stratospheric chlorine (EESC) curve. The long-term changes in the station's equivalent latitude (indicative of vortex size/position in winter and spring) are derived from MERRA (Modern Era Retrospective-analysis for Research and Applications) reanalyses at $\sim 2$ and $\sim 50 \mathrm{hPa}$. These data are used to attribute some of the upper and middle stratospheric ozone changes to the changes in vortex position relative to the station's location. In addition, high correlation of the Southern Hemisphere annular mode (SAM) with polar upper stratospheric ozone during years of maximum solar activity points toward a strong relationship between the strength of the Brewer-Dobson circulation and the polar stratospheric ozone recovery. In the lower stratosphere, ozone recovery attributable to CFCs (chlorofluorocarbons) is
\end{abstract}

still not definitive, whereas the recovery of the upper stratosphere is slower than predicted. Further research indicates that dynamical and other chemical changes in the atmosphere are delaying detection of recovery over this station.

\section{Introduction}

The history of depletion of stratospheric ozone over Antarctica in the austral spring is well known and well documented from the time of its discovery (Farman et al., 1985). The rapid increase in the loss of the lower stratospheric ozone that occurred during the 1980s (Solomon, 1999) is now being followed by a leveling off of the annual depletion (Salby et al., 2011). The cause of this depletion over the Antarctica is well known, where the excess stratosphere chlorine from manmade chlorofluorocarbons (CFCs) depletes ozone through the heterogeneous chemical reactions at low stratospheric altitudes driven by low atmospheric temperatures (Molina and Roland, 1974; Solomon et al., 1986). In the upper stratosphere, the gas-phase reactions are driving the depletion of the ozone layer, and the rate of the depletion is closely related to the levels of the ozone-depleting substance. The first stage of the atmospheric response to the implementation of the 1987 Montreal Protocol and subsequent revisions, a lessening in the ozone reduction, has been noted in the northern 
midlatitudes (Newchurch et al., 2003). The second-stage response, a statistically significant ozone increase, has not yet been detected (Solomon et al., 2005; WMO, 2011). Over Antarctica, no stage of recovery has been detected (WMO, 2011; and references therein).

The Dobson ozone spectrophotometer measurements provide not only estimates of total ozone column above the surface, but also vertical profile information. The Umkehr technique has been used since the 1930s (Götz et al., 1934) to derive the vertical ozone profile from zenith sky measurements. The algorithm is described elsewhere (Petropavlovskikh et al., 2009). We investigate the information in the data from the Syowa ground-based station $(69.0 \mathrm{~S}, 39.6 \mathrm{E})$, which has been collecting ozone profiles from Dobson-Umkehr measurements since 1977 (Miyagawa et al., 2009a), for longterm changes in the upper and middle stratospheric ozone. The re-evaluated Umkehr data-sets from the Syowa Japanese ground-based Dobson station (Miyagawa et al., 2009b) are used for this study (Sect. 2). We compare and verify the analysis of the ground-based measurements with the recently released SBUV (Solar Backscatter Ultraviolet Instrument) merged ozone data set version 8.6, overpass data. We discuss our findings in Sect. 3.

In this paper we concentrate on analysis of the long-term changes in the upper, middle and lower stratospheric ozone concentrations in Antarctica. In the upper stratosphere the interannual variability is mostly controlled by chemical reactions and is strongly influenced by the anthropogenic ozonedepleting substances (ODS). Thus, the upper stratosphere should be the best place for detection of ozone recovery (Newchurch et al., 2003). The high interannual variability in the Antarctic region and the changes in the atmosphere from other factors since 1977 must be well quantified to be able to detect the signal in the middle- and low-stratospheric ozone due to ODS. This paper assesses long-term trends in ozone profile measurements at the Syowa station during the austral spring and summer season. The statistical method used in the analysis is similar to the one described in Reinsel et al. (2002). Section 4 describes a number of well-known proxies that are used in the statistical model to remove the effects of both inter- and intraannual variability in ozone data. The ODS concentrations are often represented by the time series of the EESC (equivalent effective stratospheric chlorine) concentration that are based on the known budgets of the anthropogenic and natural sources of CFCs, halogens and bromines, understanding of the lifetime of these species in the atmosphere, and estimates of the transport/mixing of ODS from the tropical troposphere to stratosphere and from the tropics to high latitudes by a meridional transport and vertical mixing (Brewer Dobson Circulation, or BDC). The ODS concentrations over the polar region (or EESC curves) are defined by the "age of the transported air" (WMO, 2011). We describe attribution of ozone variability to the proxies in Sect. 5 and discuss differences in factors that affect upper, middle and lower stratospheric ozone over Syowa, as well as differences found between the spring and summer seasons.

\section{Ozone data sets}

Umkehr ozone profile measurements at the Antarctic station Syowa $\left(69.0^{\circ} \mathrm{S}, 39.6^{\circ} \mathrm{E}\right)$ are typically possible from late $\mathrm{Au}-$ gust to April. About 1508 data records were acquired by the Japanese Antarctic Research Expedition at the Syowa station between 1977 and 2011. Approximately 10\% were removed by a data quality evaluation, leaving 1360 profiles (August-December: 828, January-April: 532) in the analysis. The fully automated system of Dobson-Umkehr measurements was introduced for more frequent and higher quality data in 1994 (Miyagawa, 1996). All Umkehr data from the Syowa station are available from the World Meteorological Organization (WMO) Ozone and Ultraviolet Data Centre in Toronto, Canada (WOUDC).

It is worthwhile to note here that each layer in Umkehr ozone profiles is defined by atmospheric pressure, such that the pressure at the top of the layer is half of the pressure at the bottom of the layer. The exception is layer 1, which defines ozone below one-fourth of the sea-level pressure (from the surface to $\sim 252 \mathrm{hPa}$ ). The geometric altitude is not available from Umkehr measurements, nor is it used explicitly in the retrieval. A very simplified approach is to multiply layer number by $5 \mathrm{~km}$ to get an approximate altitude for the bottom of the layer, i.e., bottom of layer eight is therefore estimated at $40 \mathrm{~km}$. To understand the vertical smoothing of the optimum statistical retrieval and vertical resolution of Umkehr retrieval we refer to Petropavlovskikh et al. (2005).

The limited data taken by Dobson instruments at the Halley $\left(73.5^{\circ} \mathrm{S}, 26.7^{\circ} \mathrm{W}\right)$, and Faraday $\left(65.3^{\circ} \mathrm{S}, 64.3^{\circ} \mathrm{W}\right)$ stations in the Antarctic region from 1957 to 1972 are also investigated and compared to the Syowa record. The data at the Halley station was acquired during the months of October (13 observations), February and March (7 observations). In addition, 40 Umkehr ozone profiles obtained at King Baudouin and 65 profiles at Faraday stations are used for the discussion of seasonal variability of stratospheric ozone prior to the ozone hole and to check the consistency with the early part of Syowa's record.

In our study, we use vertical profiles of ozone derived from the measurements by the SBUV instruments on NASA's Nimbus-7 satellite and SBUV/2 instruments on NOAA-9, $11,-16,-17$ and -18 satellites. The data record begins in October 1978 and is nearly continuous until the present. Longterm upper stratospheric ozone data from the SBUV(/2) series of instruments are compared with Umkehr ozone measurements taken over the Syowa station. The satellite ozone data are retrieved using V8.6 (DeLand et al., 2012; Bhartia et al., 2013; McPeters et al., 2012). V8.6 data differ from V8 by the use of different ozone climatology, absorption cross section, OMI-based cloud height climatology and an 
internal cross-calibration technique without external adjustment (DeLand, et al., 2012). Currently, there are several sets of the SBUV(/2) V8.6 data that are available: (1) individual unadjusted satellite records that periodically overlap, (2) zonally averaged and merged ozone data (MOD) time series (http://acd-ext.gsfc.nasa.gov/Data_services/merged/) or (3) a statistically adjusted cohesive SBUV time series (available from NOAA/NWS). In this paper we present results from V8.6 MOD overpass (OP) data for which the selection of each NOAA or Nimbus satellite observation is done through quality assurance, orbit position and error analysis, creating a merged time series of the SBUV V8.6 ozone profiles. All of NOAA-9, NOAA-14 after June 2001, NOAA-16 after June 2007, and NOAA-17 after December 2010 are not included in the MOD product due to data quality, grating drive errors or rapidly drifting orbits. In order to carry out the most relevant comparisons with ground-based data, satellite data are selected for the Syowa station overpass conditions, which limits data for time coincidences within $24 \mathrm{~h}$ of Umkehr measurements and for locations within the $4^{\circ}$ by $4^{\circ}$ box centered at the geophysical location of the Syowa station. For comparisons with Umkehr data we interpolated MOD OP ozone profiles (defined by the 21-pressure-level scheme) to 10 standard Umkehr layers. We hereafter refer to this data set as MOD OP.

\subsection{Uncertainty in Umkehr ozone profile retrieval}

Umkehr observations have been routinely conducted at the Syowa station in Antarctica for more than 30 years. We are working with a data set of Umkehr profiles from the station, re-evaluated as described in details by Miyagawa et al. (2009a). This careful homogenization of the record was necessary due to the number of different Dobson instruments used at the station, as different instruments produce different profiles as seen in previous Dobson intercomparison campaigns. These differences are considered to be related to the differences in the material and quality of the individual instrument's optics, and to effects of the out-of-band scattered light inside of the instrument (Petropavlovskikh et al., 2005, 2008).

For our analyses, the Syowa data are processed by the UMK04 (Umkehr retrieval algorithm ca. 2004; Petropavlovskikh et al. (2005) algorithm modified to include an updated a priori information for $60-70^{\circ} \mathrm{S}$ latitude, based on the MLS 2007 climatology for high latitudes (McPeters et al., 2007). We also restrict the input data to the solar zenith angle range of $80-90^{\circ}$, as this range is available throughout the entire record. This restriction also means that data is used from a shortened time period within the measurement, an important consideration in the highly dynamic atmosphere encountered during the austral spring at this location. As the solar azimuth is also changing appreciably during the time of the measurements the information retrieved by the groundbased instrument is coming from different sources (Hendrick et al., 2011). The geometry of the measurements becomes critical in the polar regions, and thus considered in intercomparisons with other instrument measurements.

The accuracy of the ozone profile derived from Umkehr measurements is limited to $\sim 5 \%$ in the upper and middle stratosphere. Moreover, there is a known bias between ozone profiles derived from Umkehr measurements and other methods. We have removed this bias by deseasonalizing the time series; thus it does not affect the trend estimates, which represent relative change in the measurement over time. The noise in the retrieval is further minimized by using seasonal averages.

\subsection{Comparison of Umkehr with MOD data}

Long-term upper stratospheric ozone data from the MOD OP data set is compared with Umkehr ozone measurements taken at the Syowa station. The left panel in Fig. 1a compares the mean ozone profile for MOD OP and Umkehr data over Syowa, the middle (b) and right (c) panels show the mean bias during spring and summer, with the error bars representing one standard deviation (SD). It is shown that Umkehr ozone is lower than the homogenized SBUV ozone by about $6 \%$ in the stratosphere, and is lower than SBUV by about $1 \%$ in the troposphere. Except possibly for lower layers in spring where the Nimbus-7 data stands apart (not shown), though within $1 \mathrm{SD}$, from the later satellites, the overall long-term trend and seasonal variation agree between the Umkehr and SBUV(/2) records in this matched day comparison.

Comparisons of the recently released MOD OP data set with the ground-based instruments are of interest for detection of interferences from the instrumental artifacts and sampling issues that can affect analysis of both satellite and ground-based data. We compared data from spring (September-November) and summer (January-March) seasons (Fig. 2a, b, respectively). The correlation coefficient is lower for comparisons during the summer season $(R=0.64)$ than for comparisons during the spring season $(R=0.85)$. Since Umkehr measurements take a relatively long time to collect data, the difference may arise from the diurnal ozone variation that might change by the time of SBUV overpass measurements. Sampling frequency is low during summer in Syowa since the sun does not set from mid-December to mid-January. Furthermore, these changes in the normalization affect only summer ozone profiles. We also found a difference in agreement when comparisons were separated into the time periods prior to and after 2001 (see Table 1). We found that the offset between the satellite and Umkehr data during the spring season did not change significantly between two time periods. However, in the earlier period the slope in the scatter plot between Umkehr and SBUV ozone data was significantly higher as compared to the comparisons during the second period, while the correlation between Umkehr and SBUV ozone was higher in the first period. The first time period is characterized by sporadic sampling 


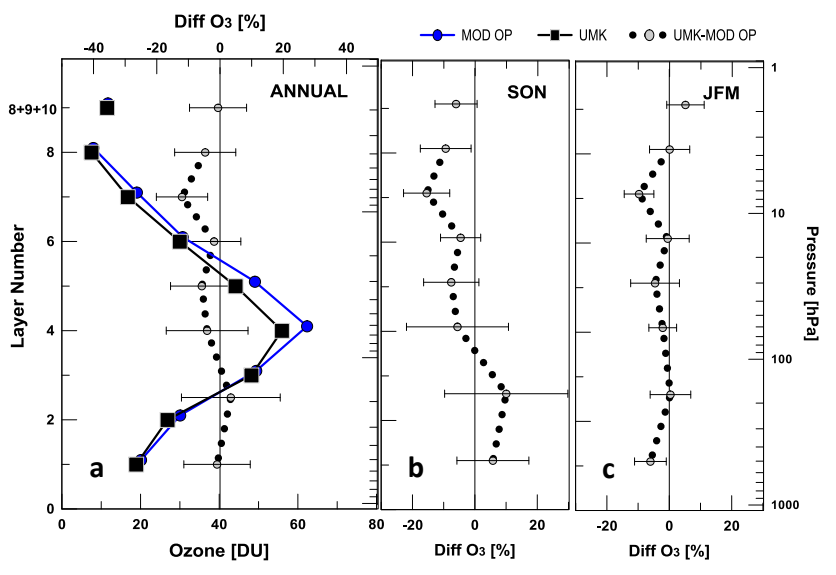

Fig. 1. Umkehr and SBUV(/2) V8.6 MOD overpass ozone vertical profile over Syowa. (a) Left panel presents annual averaged profiles for Umkehr (UMK) and SBUV, V8.6 overpass (MOD OP). The broken line shows the mean bias of annual average, with the error bars representing one standard deviation. (b) Percent difference ([UMK- MOD OP] / MOD OP - 100) between Umkehr and SBUV V8.6 MOD OP ozone measured in spring over the Syowa station. Difference is shown as function of altitude (layer). The dotted line is the mean difference for the entire period of comparisons. The uncertainty ( \pm 1 sigma) of comparisons is shown as a horizontal line. (c) Same as (b) but for summer.

in Umkehr measurements that complicates interpretation of high ozone variability due to effects of El Niño SouthernOscillation (ENSO) and aerosols from Pinatubo's volcanic eruption. Analyses of the scatter plot between Umkehr and SBUV ozone data for the summer season show that both the slope of the linear fit and correlation are reduced in the second period of comparisons. The reduction in the correlation could be related to the smaller range in ozone variability and not necessarily to errors in the data (Fioletov et al., 2006). The summary of the correlation between SBUV and Umkehr data taken on the same day for individual months and seasonal averages is shown in Table 1.

\section{Trend evaluation}

Strong interannual and seasonal variability in stratospheric ozone over Syowa requires statistical models to attribute long-term changes to natural and anthropogenic sources (WMO, 2011 and references therein). The commonly used regressions against the solar cycle and quasi-biennial oscillation (QBO) phase include the analysis of the residuals to determine the statistical significance of derived trends (Reinsel et al., 2002; Newchurch et al., 2003). In addition, interannual ozone variability was associated with natural variability mechanisms including well-studied Arctic and North American oscillations (Steinbrecht et al., 1998; Appenzeller et al., 2000; Weiss et al., 2001; Reinsel et al., 2005; Zanis et al., 2006; Yang et al., 2008; Krzyścin et al., 2009, WMO, 2011

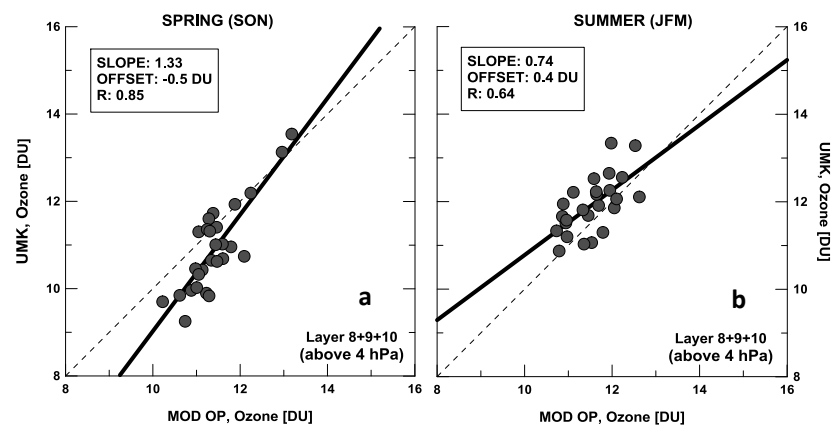

Fig. 2. Scatter plots of seasonally averaged Umkehr and SBUV V8.6 MOD overpass ozone in combined layers 8, 9 and 10 (above $4 \mathrm{hPa}$ ). Symbols represent seasonal averages of the data restricted by the $24 \mathrm{~h}$ coincidence criteria. The legend at the top of each plot provides information on the slope of the linear fit in the data, offset (calculated as the mean difference between UMK and MOD OP ozone in DU), and correlation coefficient. Data comparisons are separated in two periods: (a) September-November, (b) JanuaryMarch.

and references within). However, most of these studies addressed ozone variability observed in the Northern Hemisphere. In this paper we include several dynamical proxies in the statistical regression model that help to capture the interannual ozone variability observed in the upper and middle stratosphere over Syowa station. The attribution of ozone variability described in this paper is specific to the processes affecting ozone at the Antarctic coastal area, and may be different for other geolocations above the Antarctic continent because the polar vortex exhibits nonzonal features during the austral spring time (Schoeberl et al., 1992; Manney et al., 1995, 1999; Jiang et al., 2008; Hitchman and Rogal, 2010; Hassler et al., 2011; and references therein).

\subsection{Statistical trend model}

The accuracy of the ozone trend analysis depends on the successful removal of natural variability from the ozone record. The statistical trend model used in this paper is defined as the first-order auto regression (AR(1)) fit of the data. The model uses several regression parameters (proxies) including seasonal cycle, effects of solar activity (SOR), QBO, Southern Annular Mode (SAM), ENSO, heat flux $\left(55-75^{\circ} \mathrm{S}\right.$ average at $10 \mathrm{hPa}$ ), and equivalent latitude (EqLat) of the station (see Sect. 3.2 for specifics of the proxies). The statistical model fit provides attributions of the above parameters to the Syowa ozone record and reduces variability in residual data prior to assessing how remaining long-term changes are related to the anthropogenic forcing (WMO, 1992). The "broken stick" model (Reinsel et al., 2002, 2005) is one method used to analyze data for linear changes before and after a chosen "turning point", which is a date that is associated with the reverse in the annual growth rate of the atmospheric ODS concentrations. The model is set to detect a change 
Table 1. Comparison of monthly averaged Umkehr ozone data with the Syowa station overpass SBUV V8.6MOD ozone, monthly averaged and integrated in combined Umkehr layers 8, 9 and 10 (above $4 \mathrm{hPa}$ ). Results are shown for spring (August-November) and summer seasons (December-April). The comparisons are also separated in three time periods. Comparisons are repeated for SBUV V8.6 OP data restricted to the same date as Umkehr measurements. The offset is calculated as difference between mean UMK and mean SBUV V8.6MOD OP data. $R$ is correlation coefficient.

\begin{tabular}{|c|c|c|c|c|c|c|c|c|c|}
\hline & \multicolumn{3}{|c|}{$1978-2001$} & \multicolumn{3}{|c|}{$2001-2011$} & \multicolumn{3}{|c|}{ 1978-2011 } \\
\hline & Slope & Offset & $R$ & Slope & Offset & $R$ & Slope & Offset & $R$ \\
\hline \multicolumn{10}{|c|}{ V8.6MOD OP } \\
\hline Spring & 1.30 & -0.5 & 0.77 & 0.90 & -1.0 & 0.79 & 1.15 & -0.7 & 0.71 \\
\hline Summer & 0.71 & +0.5 & 0.57 & -1.03 & -0.5 & 0.28 & 0.64 & +0.4 & 0.42 \\
\hline \multicolumn{10}{|c|}{ V8.6MOD OP same day } \\
\hline Spring & 1.34 & -0.3 & 0.87 & 1.02 & -0.8 & 0.80 & 1.33 & -0.5 & 0.85 \\
\hline Summer & 0.90 & +0.3 & 0.69 & 0.39 & +0.5 & 0.52 & 0.74 & +0.4 & 0.64 \\
\hline
\end{tabular}

in the linear trend after the "turning point" and to estimate statistical significance in this change by using the cumulative sum (CUSUM) method (Reinsel et al., 2002; Newchurch et al., 2003). Another approach is to use the EESC curve as one explanatory parameter and assess changes in the data that agree or disagree with the prescribed rate of increase and reduction of the ODS concentrations in the atmosphere (Zanis et al., 2006). Equation (1) describes the multiple regression model, which consists of linear terms (linear trend and change in trend) and/or several proxies that account for the anthropogenic and natural variability of ozone as described above (Reinsel et al., 2002, 2005; Yoshimatsu et al., 2005).

$[Y]_{t}=a_{0}+a_{1}\left[X_{1}\right]_{t-\mathrm{d} t 1}+a_{2}\left[X_{2}\right]_{t-\mathrm{d} t 2}+\ldots+a_{m}\left[X_{m}\right]_{t-\mathrm{d} t m}+e_{t}$

Here, $X_{m}$ is the explanatory parameter, $a_{0}$ is an intercept, $a_{m}$ is a partial regression coefficient, $e_{t}$ is the unexplained noise term assumed to be autoregressive with time lag of 1 month, $t$ is a number of months from January 1979 , and $\mathrm{d} t$ is the optimum lag value of the proxy. Statistical model analysis is performed on monthly averaged data.

\subsection{Proxy data sets}

Variations in the Brewer-Dobson circulation (BDC), in wave activity, and in the polar vortex all contribute to the observed distribution of ozone (e.g., Manney et al., 1995; Jiang et al., 2008; Hitchman and Rogal, 2010). Conversely, ozone depletion has been shown to affect the circulation in the Antarctic's stratosphere and troposphere (e.g., Thompson and Solomon, 2002; Li et al., 2010; Oman et al., 2010, Son et al., 2010).

Table 2 summarizes the proxy data sets used in the statistical model (1) and their sources. The SOR index is represented by the solar flux $(3.750 \mathrm{MHz})$ observed by the National Astronomical Observatory of Japan. SOR is related to ozone changes in the long-term time series via chemical reactions in the stratosphere and effects of transport changes in the troposphere (e.g., Lu et al., 2009, 2011; Haigh et al.,
2010; Oberländer, 2012). Volcanic aerosols deplete stratospheric ozone through heterogeneous reactions on aerosol surfaces, changes in photochemistry and temperature dependency of chemical reactions (Mäder et al., 2007). However, in the case of the Umkehr data set, the aerosol optical depth (AOD) is used as a proxy in the statistical model (see discussion in Sect. 3.5 on time lag) only to remove errors associated with inability of the retrieval algorithm to interpret Umkehr measurements during interference of high loads of stratospheric aerosols in the events of volcanic eruptions (Petropavlovskikh et al., 2005). AOD is defined as monthly averages of aerosol optical depth derived from the composite of stratospheric aerosol measurements over $40-50^{\circ} \mathrm{N}$ and is adjusted to $320 \mathrm{~nm}$ to match spectral measurements in the Umkehr method (Stevermer et al., 2000).The proxy captures elevated aerosols during El Chichon (1982-1983) and Pinatubo (1991-1993) volcanic eruptions. The $40-50^{\circ} \mathrm{N}$ AOD proxy is further adjusted to account for the transport from the middle to high latitudes by application of the time lag (see further Sect. 3.5). In order to check the representativeness of the $40-50^{\circ} \mathrm{N}$ proxy for the Syowa station $\left(69^{\circ} \mathrm{S}\right)$, we compared it against the NASA AOD zonally averaged data centered at $74.3^{\circ} \mathrm{S}$ (http://data.giss.nasa.gov/ modelforce/strataer/). The $40-50^{\circ} \mathrm{N}$ AOD proxy compared well against the NASA/GISS (Goddard Institute for Space Studies) monthly mean aerosol optical depth data-set (Sato et al., 1993) at capturing the relative elevation of stratospheric aerosol load in the 1980s and 1990s.

The QBO is a $28-29$ month cycle in the tropical stratospheric winds (Baldwin et al., 2001, and references therein), and is represented in the regression model by the record of zonal winds at $50(\mathrm{QBO} 50)$ and $30 \mathrm{hPa}(\mathrm{QBO} 30)$ over Singapore $\left(1^{\circ} \mathrm{N}, 104^{\circ} \mathrm{E}\right)$ (Freie Universität Berlin Physics of the Middle Atmosphere). ENSO (Diaz and Markgraf, 1992) can generate Rossby wave trains traveling from the tropics towards the Poles, and contributes to coupling between the stratosphere and troposphere over Antarctica (e.g., Hoskins 
Table 2a. List of the proxies and sources.

\begin{tabular}{|c|c|c|c|}
\hline Proxy & Short hand & Organizational source & Web link \\
\hline Solar activity index & SOR & National Astronomical Observatory of Japan & http://www.nao.ac.jp/E/; http://solar.nro.nao.ac.jp/norp/data/daily \\
\hline Quasi-biennial oscillation & QBO & $\begin{array}{l}\text { Freie Universität Berlin Physics of the Middle } \\
\text { Atmosphere (FUB) }\end{array}$ & http://www.geo.fu-berlin.de/en/met/ag/strat/produkte/qbo/index.html \\
\hline $\begin{array}{l}\text { Southern Hemisphere } \\
\text { Annular Mode index }\end{array}$ & SAM & British Antarctic Survey & http://www.antarctica.ac.uk/met/gjma/sam.html \\
\hline El Niño-Southern Oscillation & ENSO & NOAA/NWS Climate Prediction Center & http://www.cpc.ncep.noaa.gov/products/analysis_monitoring/ensostuff/ensoyears.shtml \\
\hline Heat flux & Heat flux & $\begin{array}{l}\text { NASA: The Modern Era Retrospective analysis } \\
\text { for Research and Applications MERRA }\end{array}$ & http://acd-ext.gsfc.nasa.gov/Data_services/met/ann_data.html \\
\hline Equivalent latitude & EqLat & $\begin{array}{l}\text { NASA: Atmospheric Chemistry and Dynamics } \\
\text { Laboratory }\end{array}$ & http://acd-ext.gsfc.nasa.gov/Data_services/met/ann_data.html \\
\hline Aerosol optical depth & AOD & NASA: Composite & http://www.esrl.noaa.gov/gmd/grad/research/aerosol.html \\
\hline
\end{tabular}

Table 2b. Lag (month) derived for each proxy (columns) and for each layer (rows) for the model 1.1 in Table 3 (spring).

\begin{tabular}{lrccr}
\hline Umkehr layer & SOR & QBO50 & QBO30 & AOD \\
\hline 1 & 2 & 4 & 8 & 11 \\
2 and 3 & 2 & 4 & 8 & 11 \\
4 & 2 & 4 & 8 & 9 \\
5 & 3 & 4 & 8 & 9 \\
6 & 7 & 3 & 9 & 0 \\
7 & 8 & 1 & 9 & 3 \\
8 & 11 & 1 & 9 & 3 \\
8,9 and 10 & 11 & 1 & 9 & 3 \\
\hline
\end{tabular}

Table 2c. The same as Table $2 \mathrm{~b}$ but for summer.

\begin{tabular}{lccrc}
\hline Umkehr layer & SOR & QBO50 & QBO30 & AOD \\
\hline 1 & 2 & 5 & 0 & 0 \\
2 and 3 & 1 & 5 & 0 & 0 \\
4 & 0 & 9 & 0 & 9 \\
5 & 0 & 9 & 0 & 0 \\
6 & 0 & 4 & 0 & 2 \\
7 & 0 & 8 & 11 & 2 \\
8 & 0 & 8 & 11 & 1 \\
8,9 and 10 & 0 & 8 & 11 & 0 \\
\hline
\end{tabular}

and Karoly, 1981; Perlwitz and Harnik, 2004; $\mathrm{Hu}$ and Fu, 2009; Ialongo et al., 2012). The ENSO index is taken from the NOAA/NCEP (National Centers for Environmental Prediction) analysis. The correlation between Syowa ozone and ENSO was calculated as function of a month and altitude (layer). To account for the SAM we apply the SAM index based on the UK's Met Office database (Marshall, 2003). A correlation between Antarctic stratospheric ozone depletion and the SAM index has been seen in observations (Thompson et al., 2005; Arblaster and Meehl, 2006; Wang et al., 2011; and references therein) and models (Perlwitz et al., 2008; Son et al., 2008; Thompson et al., 2011). The largest variability in the Antarctic stratosphere associated with the SAM signal is observed in the September-December period (Fogt et al., 2009).
The correlation of ozone with meridional temperature gradients and winds is represented by the heat flux, which increases from winter to spring as a result of increasing wave activity (Fusco and Salby, 1999; Newman et al., 2001; Randel et al., 2002). Daily values of the heat flux averaged between 45 and $75^{\circ} \mathrm{S}$ since 1979 are obtained from the NASA Modern Era Retrospective-analysis for Research and Applications (MERRA) reanalysis (Rienecker et al., 2008, 2011). Since the heat flux is a highly variable parameter, only days that are coincident with Umkehr measurements are used in monthly averages. The MERRA reanalysis was also used to calculate EqLat on several isentropic surfaces to examine possible trends in the position of the polar vortex with respect to Syowa. The EqLat proxy is used to account for large changes in ozone that may result from measuring inside versus outside the vortex at altitudes where there are strong ozone gradients across the vortex edge. Such changes may be very important in long-term trend analysis since the patterns of the vortex position have changed over the years (e.g., Hassler et al., 2011). Figure 3a indicates an apparent long-term decrease in the station's EqLat at $1300 \mathrm{~K}$ (near $3 \mathrm{hPa}$ ) and $850 \mathrm{~K}$ (near $10 \mathrm{hPa}$ ), corresponding to a generally more "poleward" location of the station (that is, the station is closer to the center of the polar vortex) in recent years. The highest correlation (0.8) between EqLat $850 \mathrm{~K}$ and upper stratospheric ozone is found in combined layers 8, 9 and 10 (above $4 \mathrm{hPa}$ or $40 \mathrm{~km}$ ) in September-November (Fig. 3b). Analysis of correlations between ozone and EqLat at $1300 \mathrm{~K}$ $(\sim 3 \mathrm{hPa}), 850 \mathrm{~K}(10 \mathrm{hPa})$ and $520 \mathrm{~K}(50 \mathrm{hPa})$ (see Figs. S1, S2 and S3 in the Supplement) indicate that the correlation of ozone above $4 \mathrm{hPa}$ with EqLat $1300 \mathrm{~K}$ is less significant than that with EqLat $850 \mathrm{~K}$ or EqLat $520 \mathrm{~K}$. EqLat $1300 \mathrm{~K}$ $(\sim 3 \mathrm{hPa})$ has a maximum correlation in August with ozone in layer $7(\sim 8 \mathrm{hPa})$, and is diminished by November, reflecting the earlier vortex breakup at higher altitudes (Manney et al., 1995; Waugh et al., 1999; and references therein). High correlations between EqLat $850 \mathrm{~K}$ and ozone profiles over Syowa are seen in layers 7 and $8(\sim 8$ and $\sim 4 \mathrm{hPa})$ during September and October. In October, a strong correlation is present in most of the layers. As the vortex area shrinks in spring, the value of EqLat representative of the vortex edge shifts to higher values. Since this happens earlier at $1300 \mathrm{~K}$ 
than at $850 \mathrm{~K}$, a particular EqLat value at $850 \mathrm{~K}$ may represent the same relationship to the vortex position later into the spring. Thus, EqLat $850 \mathrm{~K}$ is selected as a proxy for the ozone regression in the period September-November. The increasing complexity of the vortex structure in the upper stratosphere in polar spring (e.g., Manney et al., 2007) may complicate interpretation of the EqLat proxy.

Figure 4 shows time series of (a) ozone monthly averages, and all proxies used in the trend model fit, such as (b) QBO, (c) ENSO, (d) solar, (e) SAM, (f) EqLat, (g) heat flux, and (h) aerosol optical depth. Heat flux is shown at $10 \mathrm{hPa}$ for a $45-75^{\circ} \mathrm{S}$ average, and EqLat is shown at $850 \mathrm{~K}$.

\subsection{EESC trend curves}

The EESC time series are used to explain ozone changes that are associated with changes in the ODS concentrations in the atmosphere (Douglass et al., 2006; Newman et al., 2006; WMO, 2007, 2011; Oman et al., 2010). The polar EESC curves have been produced with settings for the model (see below) that correspond to different assumptions regarding the mean age of air (how long it takes to transport the air with ODS chemicals from surface to stratosphere in the tropics, and then from the tropics to high latitudes) and by assuming the number of years (typically half of the age) to define the width of the air spectrum that depends on the lifetime of the ODS chemicals and transport pathways that change with the altitude and latitude of the observations. The effective chlorine includes all chlorine and bromine atoms of halogen species that destroy ozone. The contribution of bromine species is enhanced by a factor that represents the greater efficiency of bromine (10 times in this case) in ozone destruction as compared to chlorine (WMO, 2011). Three sets of EESC time series are used in the analysis of the ozone records. The EESC curves are generated by the Goddard automailer (http://acdb-ext.gsfc.nasa.gov/Data_ services/automailer/index.html). Figure 5 shows the time series of three sets of EESC curves after normalization to zero at the beginning of 1979. The first set (black line in Fig. 5) is chosen to represent EESC concentrations for the midlatitude upper stratosphere. It is based on the choice of 4 years for age of air, 2 years for air spectrum width distribution, and the 2010 WMO scenario for the ODS fractional release rates (Newman et al., 2007; Oman et al., 2009). However, the mean age of air varies with altitude and latitude (Waugh and Hall, 2002) and changes over time (Douglass et al., 2008; Waugh, 2009).

We chose two additional EESC sets generated by the NASA Goddard automailer to represent the effective chlorine levels for the South Pole stratosphere. The first curve (Polar 2) is based on 5.5 years of age of air and reaches its maximum in 2001. The second polar curve (Polar 3) exhibits a maximum in 2008. It is modeled using 10 years to define the mean age of air at upper stratospheric levels at high latitudes. This number is based on the MIPAS (Michelson Inter- ferometer for Passive Atmospheric Sounding) measurements of $\mathrm{SF}_{6}$ that Stiller et al. (2008) used to determine time for tropospheric air masses to be transported to the stratosphere and across the latitudes. These authors presented the zonally averaged $\mathrm{SF}_{6}$ data taken onboard the Envisat satellite in 20022004 as a function of altitude and latitude. The analysis of the 2002-2004 period of MIPAS satellite measurements of the $\mathrm{SF}_{6}$ and $\mathrm{CO}_{2}$ suggests that the average mean age of air for the polar stratosphere is about 10 years. However, the authors also noticed high interannual and seasonal variability in the age of air, which they suggest is related to mesospheric intrusions of $\mathrm{SF}_{6}$-depleted air into polar stratosphere at the end of the winter season. EESC represents the man-made increase in the ozone-depleting substances; it is separated from other proxies to emphasize the purpose of trend analysis, to answer the question if observed polar stratospheric ozone is showing signs of recovery after the ODS has been observed to decline since 1996.

\subsection{Cross correlation of proxies and influence on ozone}

The subsets of the above described proxies were selected to match the dates of Umkehr measurements. The data sets were then checked for cross correlations and none were found. All tested proxies are independent from each other; their correlation is close to zero. However, the amplification of some signals during different phases of dynamical activity are discussed in this section. We separated the 11 years of solar activity into high solar (HS) and low solar (LS) activity in the solar cycle. The strength of the solar activity is based on the average of the SOR of late spring (from July to December) from Southern Hemisphere winter. Therefore, HS years are 1978-1982, 1988-1992, and 1998-2002, whereas LS years are 1971-1977, 1983-1987, 1993-1997, and 20032011. Based on the selected periods of HS and LS, the subsection of SAM index and ozone time series are formed prior to correlation analysis. The HS and LS correlations are similarly analyzed for subsets of the ENSO and QBO time series. Cross correlation of Umkehr ozone monthly mean data and a proxy without separation into HS and LS years is shown in the Supplement (see Figs. S4, 5, 6, 7 and 8).

The studies of Lu et al. (2009) and Kuroda et al. (2005) showed that the 11-year solar cycle and associated change had detectable effects on the stratospheric and tropospheric circulation. In this study, we examine the relationship of the HS activity years to the SAM index (Fig. 6a). High correlation is found between ozone and SAM from separate HS years (1978-1982, 1988-1992, and 1998-2002). Significant levels of correlation between SAM and ozone are observed during austral spring throughout the entire stratosphere (layer 3 and above) with maximum correlation reaching 0.9 at $\sim 10 \mathrm{hPa}$ in September (Fig. 6a, left panel). The high correlation of the SAM with polar upper stratospheric ozone during years of maximum solar activity points toward a strong relationship between the strength of 

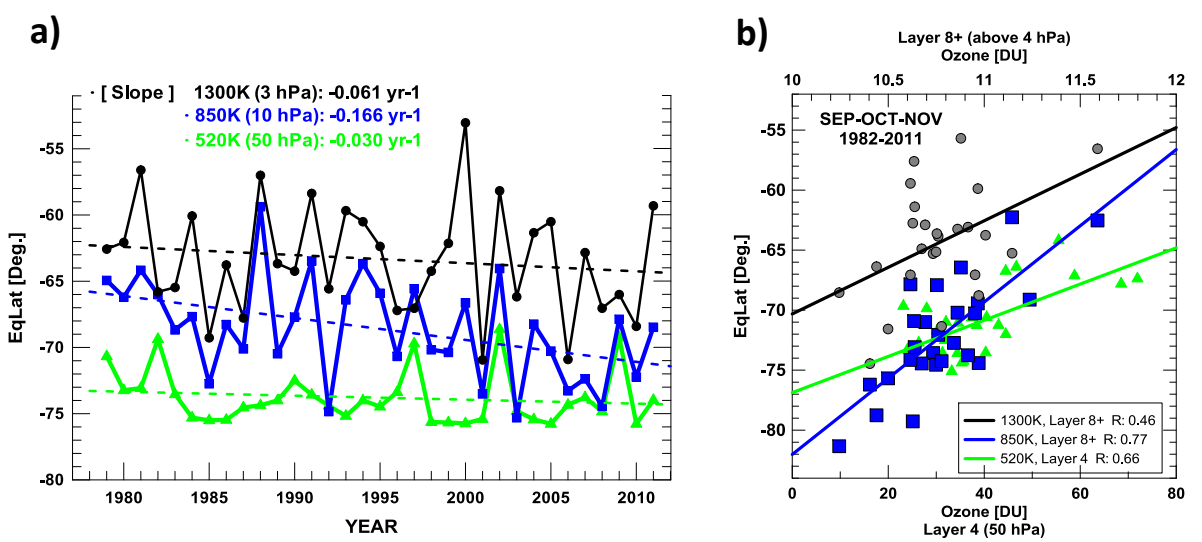

Fig. 3. Time series and ozone scattering for EqLat. (a) Time series of the difference between equivalent latitude and Syowa station latitude $\left(69^{\circ} \mathrm{S}\right)$ are plotted for the 3-month mean (September-October-November). The equivalent latitude is derived from MERRA analysis at $1300 \mathrm{~K}$ or $3 \mathrm{hPa}$, at $850 \mathrm{~K}$ or $10 \mathrm{hPa}$ and at $520 \mathrm{~K}$ or $50 \mathrm{hPa}$. (b) EqLat $(1300 \mathrm{~K}$ or $3 \mathrm{hPa}, 850 \mathrm{~K}$ or $10 \mathrm{hPa}$ and $520 \mathrm{~K}$ or $50 \mathrm{hPa}$ ) and Umkehr ozone (combined layers 8,9 and 10 or above $4 \mathrm{hPa}$ and layer 4 or $50 \mathrm{hPa}$ ) are in the 3-month mean scatter plot(September-October-November). Umkehr ozone and EqLat data are coincident within $24 \mathrm{~h}$. Umkehr data have the SOR and QBO cycles removed.

the Brewer-Dobson circulation and polar stratospheric ozone recovery. Since the SAM and upper stratospheric ozone are both affected by planetary wave propagation, their correlation reflects their response to the same mechanism, especially during years with high solar activity. The increase in the downward planetary polar wave driving during austral spring since 1979 (Harnik et al., 2011) is affected by changes in the vortex structure at the upper stratosphere levels and by the delayed breakup of the vortex. This is supported by correlation analysis of Syowa ozone data. Additionally, an interesting correlation between SAM and lower stratospheric and tropospheric ozone (at altitudes below $\sim 30 \mathrm{hPa}$ ) is found in December during both HS and LS periods of the Umkehr record. It points to the long-term influence of the polar ozone hole on the interannual variability of the SAM in the summer troposphere (December).

The change in sea level pressure due to the ENSO phase affects the westerly winds in the Southern Hemisphere, which therefore creates a stronger polar vortex (SAM index), and affects the polar ozone (Hu and $\mathrm{Fu}, 2009)$. The similarity in the response of ozone change to ENSO and SAM variability was assessed though analysis of Umkehr data. First, the above-described correlation analysis between SAM and ozone was repeated to assess temporal and seasonal relation between ozone and the ENSO index. The Syowa ozone time series and ENSO index were separated into subsets of data during periods of high and low solar cycle activity (see discussion above). Figure $6 \mathrm{~b}$ shows a correlation between ozone and ENSO as function of altitude and month, where the left and right panels show results for the HS (maximum) and LS (minimum) time periods. We find that during HS periods, ENSO is robustly correlated $(R=0.6)$ with ozone in the troposphere and lower stratosphere (layers $1-6$ or below $\sim 10 \mathrm{hPa}$ ). Note that during November and December the correlation plot between SAM and ozone (Fig. 6a) depicts fairly similar but negative temporal patterns as compared to the results shown in Fig. 6b. By January, the correlation in the lower stratosphere and troposphere disappears, and ozone in the middle stratosphere (layers 4-6) continues to be correlated with ENSO $(R=0.6)$ until March. In the upper stratosphere (layers 6-9) during the HS period more than $25 \%(R=0.5)$ of ozone variability in December is inversely related to the ENSO. At the same time, during the LS years the correlation between ENSO and ozone is positive in November and December with maximum correlation $(R=0.7)$ found in layer 8 . These results indicate that the coupling between the stratosphere and troposphere over Antarctica (e.g., Hu and Fu, 2009; Harnik et al., 2011; Ialongo et al., 2012 and references therein) preferably happens in the HS period. During LS years (Fig. 6b, right side) a weak (0.4) correlation between middle stratospheric ozone (layer 5) and ENSO is found in November, which completely disappears in December. At the same time, Fig. 6a shows weak anticorrelation between ozone and SAM in November $(-0.4)$, which strengthens in December $(-0.6)$ in the lower stratosphere and troposphere. Our findings support the previous studies that found high anticorrelation of ENSO with SAM index (Haigh and Roscoe, 2006), except we find it true mostly during austral spring in HS years.

During the austral summer, L'Heureux et al. (2006) found high correlations between SAM and ENSO variability near the surface and determined that $25 \%$ of the SAM interannual variability is linearly related to ENSO. In addition, Fogt and Bromwich (2006) determined that during the 1990s at sea level pressure and at high latitudes the ENSO signal was amplified when it was in phase with SAM. In our analysis of relation between ozone variability and SAM (Fig. 6a) no significant correlation is found near the surface during austral 


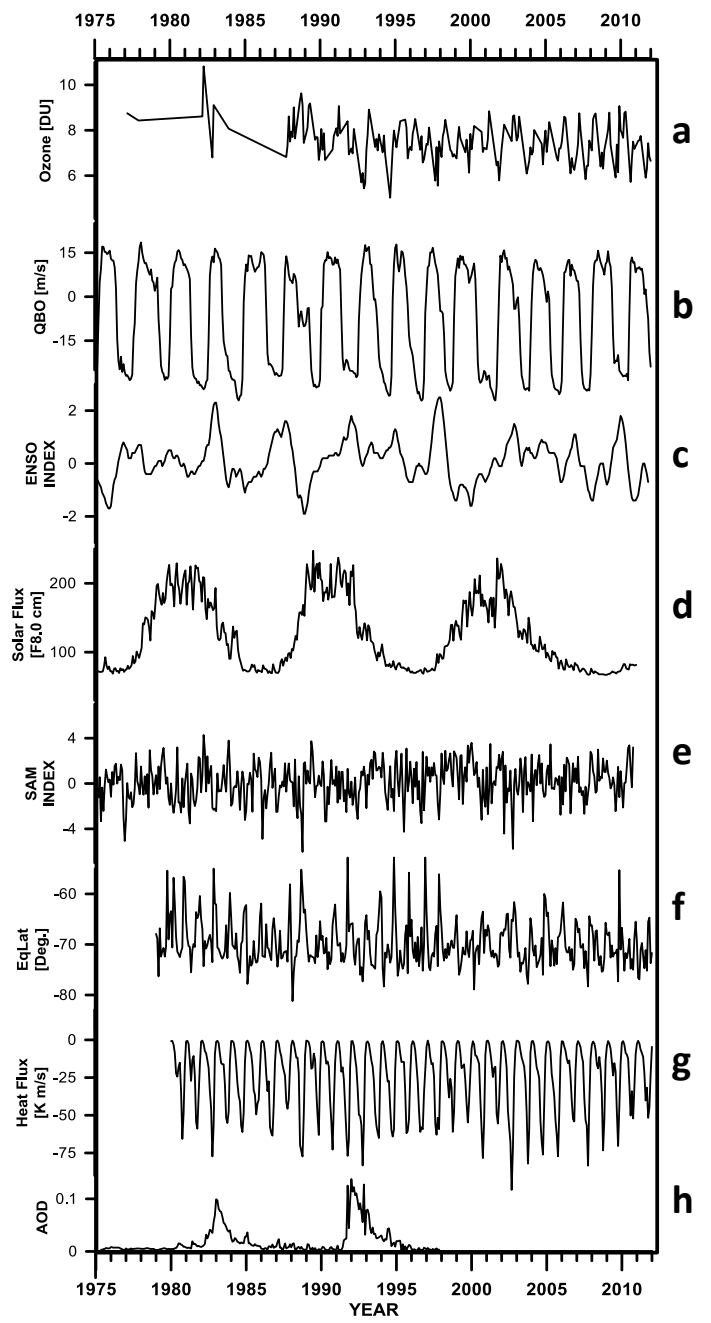

Fig. 4. Contribution of proxies to the ozone variability. Time series of monthly average variability showing (a) Umkehr layer 8 ozone, (b) QBO (30 hPa), (c) ENSO index, (d) solar flux $(3.75 \mathrm{GHz})$, (e) SAM index, (f) equivalent latitude $(850 \mathrm{~K})$, (g) heat flux (45 day mean, wave $1-3,45-75^{\circ} \mathrm{S}$ average at $10 \mathrm{hPa}$ ), and (h) AOD.

summer for either HS or LS periods. We repeated correlation analysis, but used the product between SAM and ENSO as proxy to study ozone variability in HS and LS years (Fig. 6c). We find that the amplification of the SAM signal in ozone variability during HS years to be related to ENSO activity in November and December, where high correlation is extended through all atmospheric levels. Relatively high correlation $(R=0.5-0.7)$ is also found in the lower stratosphere and troposphere during March and April in HS years. No significant amplification of ENSO and SAM index in ozone variability is detected in LS years, if not the opposite occurs in December where relatively strong negative correlation $(R=0.6)$ between SAM and low stratosphere ozone is reduced in the product $(R=0.4)$. Therefore, the relationship between ozone variability and the ENSO or SAM signal is

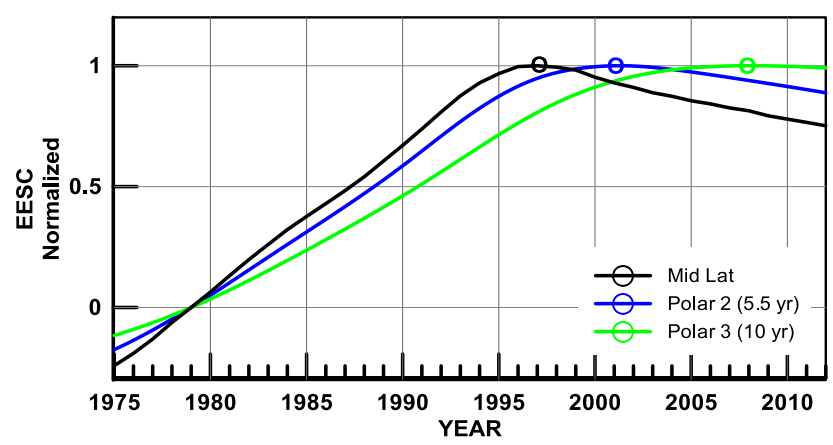

Fig. 5. EESC curve represents estimates of chlorine-equivalent concentrations of chemicals in the stratosphere associated with longterm changes in the ozone-depleting substances. Midlatitude curve (black line) shows the EESC estimate based on the 2010 WMO scenario. For polar stations, Polar 2 curve (blue) is based on 5.5 years of mean age of air of the 2010 WMO scenario. Polar 3 curve (green) shows the EESC time series based on the assumption of 10 years for the mean age of air. The circle point indicates the peak of chlorine concentration for each EESC curve.

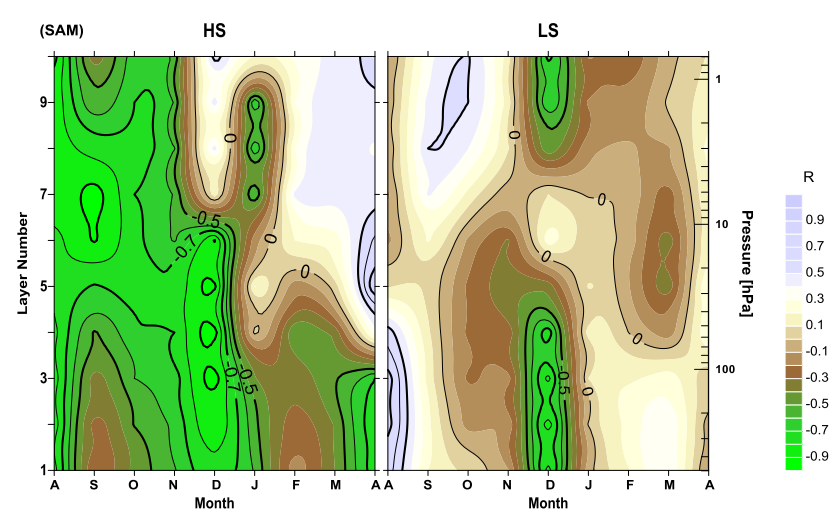

Fig. 6a. Plots show correlation $(R)$ between ozone and the mean SAM index as function of altitude (Umkehr layers) and month. Correlation between the SAM index and Umkehr ozone is shown for high (left) and low (right) solar activity in the solar cycle (maximum and minimum of the solar cycle respectively). Results are shown as function of month and altitude (Umkehr layers).

highly nonlinear, where the SAM's decadal changes might enable shifts in climate regimes (Yuan and Yonekura, 2011).

Analysis of correlation between ozone and QBO winds at $50 \mathrm{hPa}$ were separated into HS and LS conditions (Fig. 6d). High negative correlation is found between layer 5 ozone and the QBO signal at $\sim 20 \mathrm{hPa}$ in the February-March periods during the $\mathrm{HS}$ years, which somewhat resembles the pattern of positive correlation found between ENSO and ozone (Fig. 6b). In addition, during HS years in September we notice high positive correlation between QBO and ozone $(R=0.5)$ in the middle stratosphere (layers 5, 6 and $7)$, which is consistent with findings of Kuroda and Yamazaki (2010) that related the impact of the 11 year solar cycle and the stratospheric equatorial $\mathrm{QBO}$ on the SAM in 


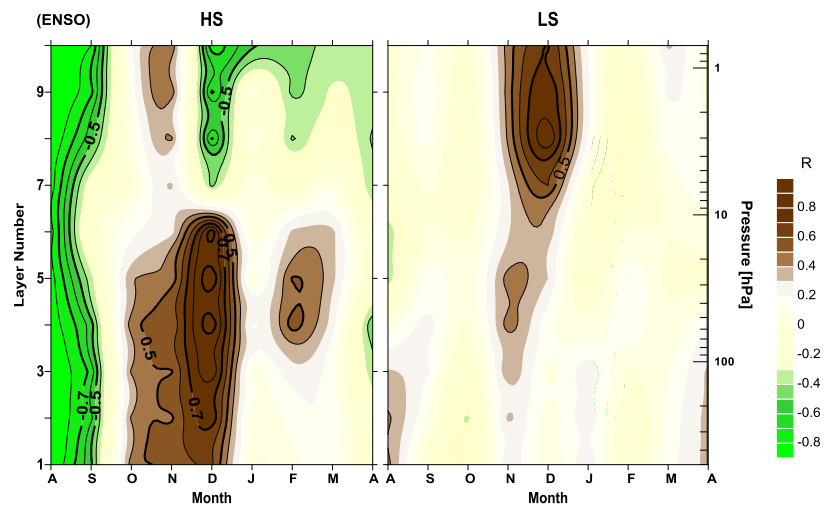

Fig. 6b. The same as Fig. 6a but for the correlation of ENSO and ozone

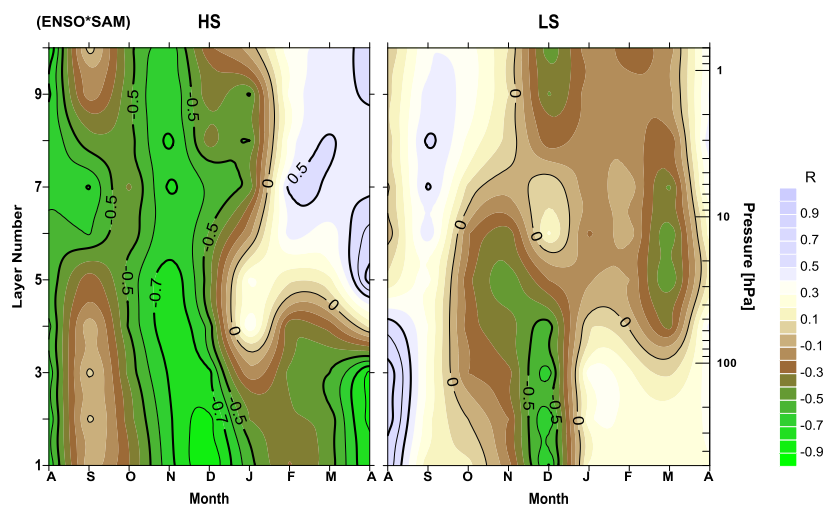

Fig. 6c. The same as Fig. 6a but for the correlation of ENSO.SAM and ozone

late winter/spring. Similar results are also found by Haigh and Roscoe (2006), when SAM variability is analyzed in relation to the compound of solar and QBO signals as compared to using these signals separately. At the same time, during the LS period we find that temporal and vertical patterns of QBO50 and ozone correlations (Fig. 6d) are similar to results for SAM and ozone correlations (see Fig. 6a). When we repeated the analysis with QBO at $30 \mathrm{hPa}$ level (Fig. 6e), in the LS period in February and March we find 0.7 positive correlation centered at $\sim 30 \mathrm{hPa}$ altitude.

Since both QBO and ENSO influence polar stratospheric temperatures and wave activity (Hamilton, 1998), and therefore ozone, it is difficult to separate the signals. Using an equatorial zonal wind data archive for the 1958-2008 period, Taguchi (2010) found ENSO-related changes in the phase and amplitude of the QBO signal that are related to the wave activity at the equatorial region. However, there are modeling studies that find stratospheric polar-temperature changes between El Niño (EN) and La Niña (LN) periods even when no QBO signal is included in the model (Sassi et al., 2004, Garcia-Herrera et al., 2006; L'Heuraeux and Thompson, 2006). Clear differences in general circulation and to-

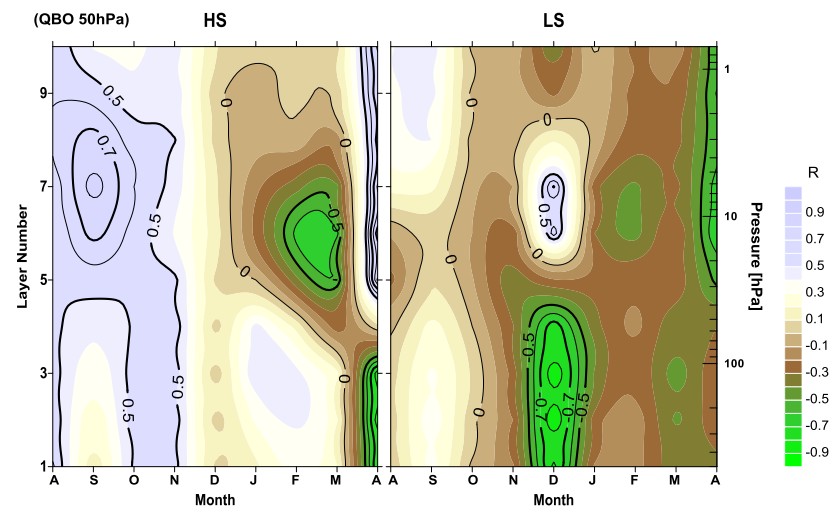

Fig. 6d. The same as Fig. 6a but for the correlation of QBO $(50 \mathrm{hPa})$ and ozone

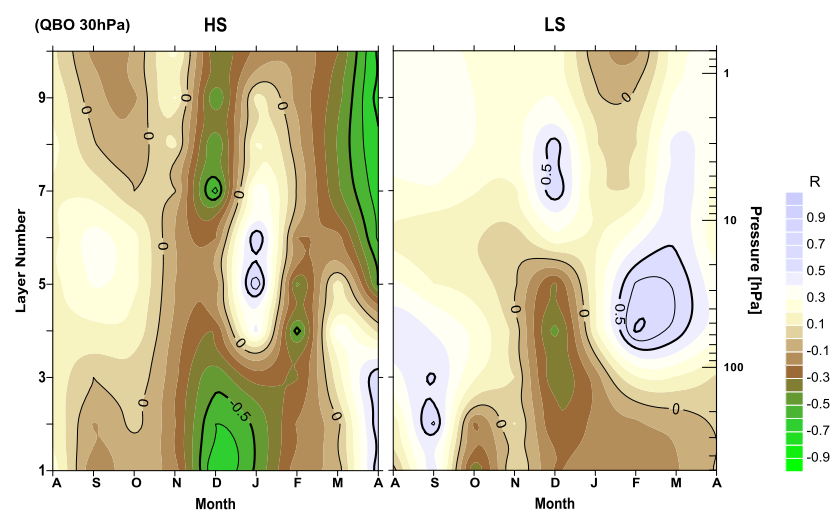

Fig. 6e. The same as Fig. 6a but for the correlation of QBO $(30 \mathrm{hPa})$ and ozone

tal ozone distribution in the Southern Hemisphere are found between LN and EN years (Garfinkel and Hartmann, 2007; Hitchman and Rogal, 2010). Hitchman and Rogal (2010) showed that in the months of August, September and October there is a strong relation between the UTLS anticyclone near the tip of South Africa (SA), wave activity, and reduction of ozone distribution that is driven by ENSO events. The Syowa station is located along the longitude that intersects the location of the South African High anticyclone, and therefore is affected by the variability in regional meridional circulation and by ENSO variability, i.e., a strong anticyclone forms near SA during the EN phase, and stronger transport of ozonepoor air masses to the high-latitude stratosphere occurs, thus affecting year-to-year variability in stratospheric ozone over the Syowa station.

Although the increase in the $30-50^{\circ} \mathrm{S}$ mean heat flux is often used for prediction of the polar-vortex breakup ( $\mathrm{Hu}$ and Fu, 2009; Harnik et al., 2011), the correlation between heat flux at $10 \mathrm{hPa}$ and EqLat at $520 \mathrm{~K}$ is found to be negligible. In the spring, when heat flux values are significant, the heat flux is anticorrelated with the size of the polar vortex. When the heat flux is enhanced, it leads to higher temperatures in 
the polar vortex, which shrinks the area of the polar vortex. However, as spring advances (i.e., from September to October and to November) the polar vortex is rarely centered over the South Pole and a wave 1 exists, which suggests that the chances for Syowa to be under the depleted ozone decrease as spring advances and the vortex shape elongates and shifts its position relative to Syowa. At the station's location, the zonal mean heat flux will not necessarily correlate well with the station's EqLat. It is suspected that the variations in EqLat at Syowa are more closely related to the vortex shape or position, while its size (area) is better correlated with the heat flux. Therefore, we use both proxies to explain ozone variability over Syowa.

Stratospheric temperature is not helpful as a proxy in our analysis because of limited availability of reliable temperature data extending into the upper stratosphere, the difficulty in defining the temperature sensitivity of upper stratospheric ozone in noisy Umkehr data, and the high correlation of temperature with other proxies (e.g., EqLat) already being considered.

Although we find the separation of data into HS and LS produces different patterns in vertical and temporal correlation of tested proxies and ozone, the patterns are quite different and not very easily combined. We attempted to multiply proxies with solar flux, but it did not improve the fit of the model. Based on the above analysis we conclude that the best approach for trend analysis is to use the entire data set without separation of time series into HS and LS periods. In order to detect if the attribution method might become nonlinear between HS and LS years it is of interest to continue assessment of ozone variability as more years with the HS conditions are acquired at the Syowa station. Current results suggest that a different approach might be necessary for creation of proxies for trend analysis. It also points out that separation of the time series into different seasons helps to eliminate nonlinearity of the statistical fit, which is the approach that we took in this paper.

\subsection{Time lag}

In order to optimize the autoregressive model that fits the observed ozone variability, an appropriate time lag must be determined for all explanatory variable time series. Results are shown in Table 2 (section $\mathrm{b}$ and $\mathrm{c}$ for spring and summer seasons respectively). For example, the application of the lag to the Singapore winds (QBO) time series has been applied in many studies of ozone trends (Zerefos et al., 1992). The lag represents the time it takes for the transport to affect ozone at higher latitudes. It is important to note here that the time lag is also altitude dependent, corresponding to different processes governing the upper, middle and lower stratosphere.

A significant influence of volcanic eruptions on total ozone was found in the northern latitudes (Mäder et al., 2007). Recent publications suggest that ozone depletion due to chemical reactions on volcanic aerosol surfaces was compensated by the QBO and EP-flux enhanced BDC transport, such that the effect of Pinatubo's eruption was not observed in the Southern Hemisphere until 1992 (Poberaj et al., 2011; Aquila et al., 2013). Note, the use of AOD proxy for analysis of Syowa ozone time series is not intended to assess chemical or dynamical effects of aerosols on stratospheric ozone. It is primarily used to remove a retrieval error due to misinterpretation of an Umkehr measurement when it is affected by the presence of scattering aerosols in the lower stratosphere (Petropavlovskikh et al., 2005). In order to account for transport of aerosols from the middle to high latitudes and to achieve the best statistical fit of the data (reduction in residual, see Table 3) a time lag for the AOD proxy is applied (see Table 2, part 2). It is found that the best fit is achieved when delaying AOD time series by 2-4 months for the upper and middle stratospheric ozone interpretation (direct effect of AOD scattering on Umkehr retrieval above $25 \mathrm{~km}$ altitude). In analysis of ozone time series below $25 \mathrm{~km}$ altitude the time lag for the best fit of the AOD proxy is estimated at 9-11 months, which likely indicates a delayed transport of volcanic aerosols to Antarctica at the lower altitudes (Aquila et al., 2012).

Garfinkel and Hartmann (2007) discussed ENSO and QBO interferences and their effects on temperature in the polar stratosphere. They found the typical lag for ENSO effects to be seen in the temperature record poleward of $70^{\circ} \mathrm{S}$ at $10 \mathrm{hPa}$ was one month or less, which was related to the anomalous heat conversion caused by the wave breaking in the stratosphere, and where the radiative relaxation happens more quickly than at $50 \mathrm{hPa}$ level (e.g., Newman et al., 2001). The time lag is likely to be similar for the upper stratospheric ozone record because of the strong temperature/ozone chemistry relationship there. Thus, no time lag was applied to the ENSO proxy. Heat flux, EqLat and SAM proxies are also used without a time lag, the appropriateness of which was verified by correlation analysis with stratospheric ozone time series, such as finding the highest correlation without the time lag as compared to with the lag applied.

\subsection{The best set of proxies for model fit}

The sensitivity of the fit by statistical model (1) to the choice of proxies is assessed by calculating the variance of the residual (VAR). Residual $(R)$ is calculated as

$R=D-$ Model,

where $D$ is seasonally mean ozone time series (spring and summer) and the model is predicted ozone by using coefficients of the multiple regression statistical fit to the $D$ (Eq. 1). We created several models by changing the set of proxies described in Sect. 3.2. For example, model 1.1 consists of two terms: long-term mean average and Polar 2, which is the EESC curve for a 5.5 years age-of-air scenario. In order to determine the best set of proxies and create the model with the most effective fit of the data, the variance of the residuals 
Table 3. Table provides a summary of the explained variance for the statistical model's fit separated into spring and summer seasons. Results are provided for Umkehr layers (columns) and for different statistical models that include several proxies (rows of the table). The top row indicates atmospheric pressure at the bottom of the Umkehr layer. The first row of the spring and summer seasons section represents the variance of the residuals calculated between monthly averaged ozone time series and a statistical model that includes seasonal and EESC Polar 2 curve parameters (deseasonalized and detrended time series). This result is considered as a benchmark and is set at $100 \%$. Other rows show results for the fit of several statistical models that include additional proxies. Results are presented as percent reduction of the variance in the residuals relative to the first row. For example, the second row shows change in the variance of the residual for the model fit that included seasonal, EESC, SOR, QBO and AOD proxies as compared to the residual of the model that had only a seasonal component and EESC proxy. Note that negative values indicate improvement of the fit and the reduction in the unexplained variance $(-10$ means that observed ozone variability in the specified Umkehr layer was reduced by $10 \%$ ). The boldface numbers in the table show the best fit of the model for the layer in each section of the table. The bold face shows the best final result of the model fit for each layer and in each season separately. EqL850K proxy represents the 1 month averages of the MERRA equivalent latitude values at the $850 \mathrm{~K}$ level that is also temporally matched with Umkehr ozone measurements (within $24 \mathrm{~h}$ ). Table 3 provides information allowing for the best choice of proxies that reduce observed-ozone variability in the most effective way.

\begin{tabular}{|c|c|c|c|c|c|c|c|c|}
\hline \multirow{2}{*}{$\begin{array}{l}\text { a) } \\
\text { Pressure (hPa) }\end{array}$} & \multicolumn{8}{|c|}{ Layer } \\
\hline & 1000 & 250 & 62.5 & 31.2 & 15.6 & 7.8 & 3.9 & 3.9 \\
\hline Spring (SON) & 1 & 2 and 3 & 4 & 5 & 6 & 7 & 8 & 8,9 and 10 \\
\hline 1.0)Seasonal variance (DU2̂) & 1.08 & 117.3 & 103.0 & 33.5 & 7.51 & 1.54 & 0.21 & 0.36 \\
\hline 1.1) $\mathrm{SOR}+\mathrm{QBO}+\mathrm{AOD}(\%)$ & -49 & -48 & -41 & -29 & -25 & -34 & -28 & -28 \\
\hline 2.1) $\mathrm{SOR}+\mathrm{QBO}+\mathrm{AOD}+\mathrm{EqL} 520 \mathrm{~K}(\%)$ & -58 & -58 & -51 & -35 & -25 & -27 & -13 & -13 \\
\hline 2.2) $\mathrm{SOR}+\mathrm{QBO}+\mathrm{AOD}+\mathrm{EqL850K}(\%)$ & -61 & -71 & -71 & -57 & -44 & -60 & -60 & -60 \\
\hline 2.3)SOR+QBO+AOD+EqL1300K (\%) & -51 & -49 & -42 & -37 & -46 & -55 & -32 & -31 \\
\hline 2.4) $\mathrm{SOR}+\mathrm{QBO}+\mathrm{AOD}+\mathrm{ENSO}(\%)$ & -56 & -55 & -47 & -34 & -25 & -34 & -28 & -28 \\
\hline 2.5) $\mathrm{SOR}+\mathrm{QBO}+\mathrm{AOD}+\mathrm{SAM}(\%)$ & -56 & -61 & -63 & -60 & -49 & -43 & -35 & -36 \\
\hline 2.6) $\mathrm{SOR}+\mathrm{QBO}+\mathrm{AOD}+\mathrm{HF} 10(\%)$ & -52 & -54 & -50 & -43 & -34 & -38 & -28 & -28 \\
\hline 3.1) $\mathrm{SOR}+\mathrm{QBO}+\mathrm{AOD}+\mathrm{EqL} 850 \mathrm{~K}+\mathrm{ENSO}(\%)$ & -56 & -67 & -69 & -62 & -50 & -46 & -42 & -41 \\
\hline 3.2)SOR+QBO+AOD+EqL850K+SAM (\%) & -56 & -68 & -74 & -70 & -56 & -46 & -42 & -41 \\
\hline 3.3)SOR+QBO+AOD+EqL850K+HF10 (\%) & -61 & -74 & -80 & -79 & -64 & -54 & -42 & -41 \\
\hline 3.4)SOR+QBO+AOD+EqL520K+SAM (\%) & -58 & -63 & -62 & -56 & -44 & -36 & -21 & -22 \\
\hline 3.5)SOR+QBO+AOD+EqL1300K+SAM (\%) & -57 & -62 & -62 & -59 & -54 & -43 & -28 & -28 \\
\hline Summer (JFM) & 1 & 2 and 3 & 4 & 5 & 6 & 7 & 8 & 8,9 and 10 \\
\hline 1.0)Seasonal variance (DU2̂) & 0.32 & 15.1 & 9.1 & 13.2 & 2.99 & 0.50 & 0.10 & 0.18 \\
\hline 1.1)SOR+QBO+AOD $(\%)$ & -20 & -2 & -25 & -33 & -35 & -16 & -18 & -18 \\
\hline 2.1) $\mathrm{SOR}+\mathrm{QBO}+\mathrm{AOD}+\mathrm{EqL} 520 \mathrm{~K}(\%)$ & -20 & -15 & -39 & -35 & -35 & -16 & -18 & -18 \\
\hline 2.2) $\mathrm{SOR}+\mathrm{QBO}+\mathrm{AOD}+\mathrm{EqL} 850 \mathrm{~K}(\%)$ & -17 & -14 & -41 & -42 & $-\mathbf{5 0}$ & -38 & -23 & -22 \\
\hline 2.3) $\mathrm{SOR}+\mathrm{QBO}+\mathrm{AOD}+\mathrm{EqL} 1300 \mathrm{~K}(\%)$ & -20 & -16 & -39 & -35 & -42 & -31 & -23 & -22 \\
\hline 2.4)SOR+QBO+AOD+ENSO (\%) & -20 & -16 & -41 & -39 & -37 & -16 & -18 & -18 \\
\hline 2.5)SOR+QBO+AOD+SAM (\%) & -20 & -22 & -59 & -37 & -35 & -19 & -18 & -18 \\
\hline 2.6) $\mathrm{SOR}+\mathrm{QBO}+\mathrm{AOD}+\mathrm{HF} 10(\%)$ & -17 & -13 & -40 & -32 & -30 & -16 & -18 & -18 \\
\hline 3.1) $\mathrm{SOR}+\mathrm{QBO}+\mathrm{AOD}+\mathrm{EqL} 850 \mathrm{~K}+\mathrm{ENSO}(\%)$ & -23 & -21 & -43 & -42 & -49 & -36 & -29 & -26 \\
\hline 3.2) $\mathrm{SOR}+\mathrm{QBO}+\mathrm{AOD}+\mathrm{EqL} 850 \mathrm{~K}+\mathrm{SAM}(\%)$ & -23 & -24 & -57 & -40 & -48 & -36 & -23 & -26 \\
\hline 3.3) $\mathrm{SOR}+\mathrm{QBO}+\mathrm{AOD}+\mathrm{EqL} 850 \mathrm{~K}+\mathrm{HF} 10(\%)$ & -23 & -18 & -44 & -37 & -45 & -42 & -29 & -26 \\
\hline 3.4)SOR+QBO+AOD+EqL520K+SAM (\%) & -20 & -22 & -56 & -36 & -35 & -19 & -18 & -18 \\
\hline 3.5)SOR+QBO+AOD+EqL1300K+SAM (\%) & -20 & -21 & -57 & -37 & -44 & -36 & -29 & -26 \\
\hline
\end{tabular}

$R$ (Eq. 2) or VAR is calculated for each model and in each Umkehr layer. Results of the first fit are used as the reference (first row in Table 3, columns are results for Umkehr layers). The difference between the variance for the tested model and the reference is calculated to find the reduction in the residual variance. The difference of the square root is normalized to the mean ozone of the layer (VAR1.0) and is presented as percent change, i.e., change of the VAR in model 2.1 from model 1.0:

(VAR2.1 - VAR1.0)/VAR1.0 100.

The model is then changed by sequentially adding individual or combination of proxies. Table 3 describes all models tested (first column provides model number and list of proxies separated by plus sign). Model 1.1 is the statistical model that predicts ozone in all Umkehr layers by including the combination of commonly used proxies SOR+QBO+AOD, 
such as SOR, QBO (QBO30 and QBO50) and AOD time series), where AOD is used to eliminate the errors in Umkehr ozone retrieval during volcanic eruptions. The numbers in front of each line in Table 3 denote different model runs using different combinations of various proxies. The best fit is determined as the largest reduction in the VAR of the residual as compared to the first set. Therefore, the best model consists of the proxies that help to explain the largest portion of the ozone variability.

We analyzed the Syowa ozone profile data to assess the difference in contribution of individual proxies between summer and spring seasons. First, we discuss results of trend model optimization for ozone measured in spring. We find that the significant reduction (40-45\% in lower stratosphere and troposphere) in ozone's interannual variability in spring is already achieved when the model contains SOR, QBO and AOD proxies, further referred to as "basic" model. We also notice that explained variance in ozone is greatly increased (by $\sim 30 \%$ in the lower layers and by $\sim 10 \%$ in the upper layers) when SAM is added to the basic model (see Table 3, model 2.5), which is consistent with previous studies (Thompson et al., 2005, 2011). However, in layers 1, 2, 3 and 4 even better fit is obtained when EqLat $850 \mathrm{~K}$ (2.2) is added to the basic model fit in place of SAM. In layers 7, 8, 9 and 10 , model 2.2 provides the best fit. In addition, we find the contribution of the heat flux (HF10) to ozone variability is comparable to the ENSO contribution in most of the layers. However, in the middle stratosphere the addition of HF10 to the basic model accounts for a higher explained variance (35-45\%) as compared to the addition of ENSO (25-35\%), but still less than what is explained by the addition of SAM (50-60 \%). Further improvement (from 57 to $79 \%$ in layer 5 and from 44 to $64 \%$ in layer 6 ) is found when the model includes SOR, QBO, AOD, EqLat $850 \mathrm{~K}$ and HF10. Although ENSO seems to improve the fit (by $\sim 7 \%$ as compared to the basic fit) in the troposphere and low stratosphere (layers 1,2, 3 and 4), the improvement is not as large as when other proxies are used. Therefore, we recommend using model 3.3 to explain ozone variability in layers $1-6$ in spring. Although, EqLat proxy does not point to a specific dynamical mechanism that is responsible for ozone variability in Antarctica, it helps to reduce ozone variability for trend analysis, and thus a better understanding of the future long-term tendencies can be achieved.

It is important to note that significant stratospheric warming over the high latitudes in the Southern Hemisphere has been derived from microwave sounding unit observations ( $\mathrm{Hu}$ and $\mathrm{Fu}, 2009$ ). Warming trends are related to the increases of the stratospheric eddy-heat fluxes (HF10) during the late-austral summer and fall, which are caused by the increase of the wave propagation into the stratosphere and adiabatic heating. Hu and Fu (2009) found a close correlation with sea-surface temperatures, which are influenced by the anthropogenic increase in the greenhouse gases. Future stratospheric warming will likely influence ozone recovery in the upper stratosphere (Waugh et al., 2009; Stolarski et al., 2010; Garcia et al., 2008). Moreover, analysis of the coupling between stratospheric ozone variability and climate changes that are affecting dynamics and meteorology of the atmosphere and oceans in the Southern Hemisphere are of great importance for future ozone level predictions.

We also analyzed summertime ozone. According to our analysis we find that solar, QBO and AOD (basic model) explain only $2-35 \%$ of the variability. However, the stratospheric ozone variability is most successfully explained by the model that includes the EqLat $850 \mathrm{~K}$ proxy in addition to the basic model. We find significant improvement of explained ozone variability in layers $5(42 \%)$ and $6(50 \%)$. The model 2.2 fit for ozone in layers $7(38 \%)$ and $8(22 \%)$ appears to have further improvement in the explained variances when HF10 proxy (model 3.3) is added (42 and 29\%). The model fit using EqLat $850 \mathrm{~K}$ and HF10 is the best for combined layers 8, 9 and 10 (although it only explains $26 \%$ ). The best fit for summer ozone variability in layer 4 (maximum of ozone layer, $59 \%$ ) is found when SAM is added to the basic model fit. However, the total improvement to the basic model fit in the summer is not as large as in spring. Moreover, most statistical models have difficulty explaining variability in layer 1: basic fit explains $20 \%$ of tropospheric ozone variability, while addition of ENSO, SAM or HF10 provides a slight improvement to $23 \%$, however none of the proxies are clearly superior. Thus, the ultimate choice of a single proxy for an improved statistical model is not possible. As discussed by L'Heureux et al. (2006), SAM and ENSO are highly correlated during austral summer, and both affect the heat flux. Moreover, it is hard to separate effects of the QBO and ENSO on polar dynamics (Hitchman and Rogal, 2010). Therefore, it is hard to separate their signals in tropospheric ozone. It is interesting to note that ozone variability in layers 2 and 3 during summer is defined by solar, AOD, QBO, EqLat $850 \mathrm{~K}$ and SAM proxies, but the model explains only $24 \%$ of variability. The inability of finding a good fit to the tropospheric and lower stratospheric ozone variability could be an artifact of using the Polar 2 EESC curve in the basic trend fit model. Further investigation is needed. Results of the above-described analysis clearly points out that the lower and upper atmosphere in the summer is driven by very different dynamical and chemical mechanisms.

Additionally, results of the correlations between data and the fitted model were analyzed (see Table T1 in the Supplement). Results are found to be somewhat different from those in Table 3 (Table T1 is organized similar to Table 3, but represents coefficients of determination instead of reduction in variance). It is not completely clear if one method is preferred over the other in deciding on significance of each proxy attribution to ozone variability. Results of both approaches (correlation and reduction in variance) are affected by the "not so perfect" fit of the EESC (Polar 2) proxy in the second half of the Umkehr record (Fig. 7). Moreover, separation of data sets into years of high and low solar activity points to changes in 
a)
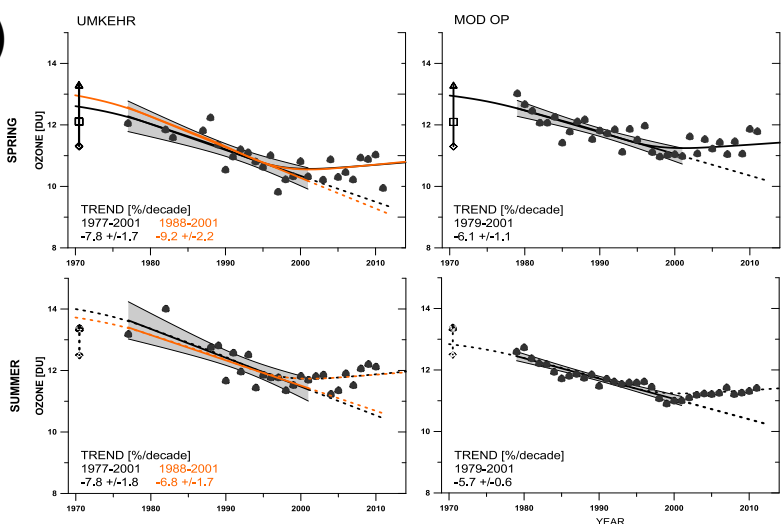

b)
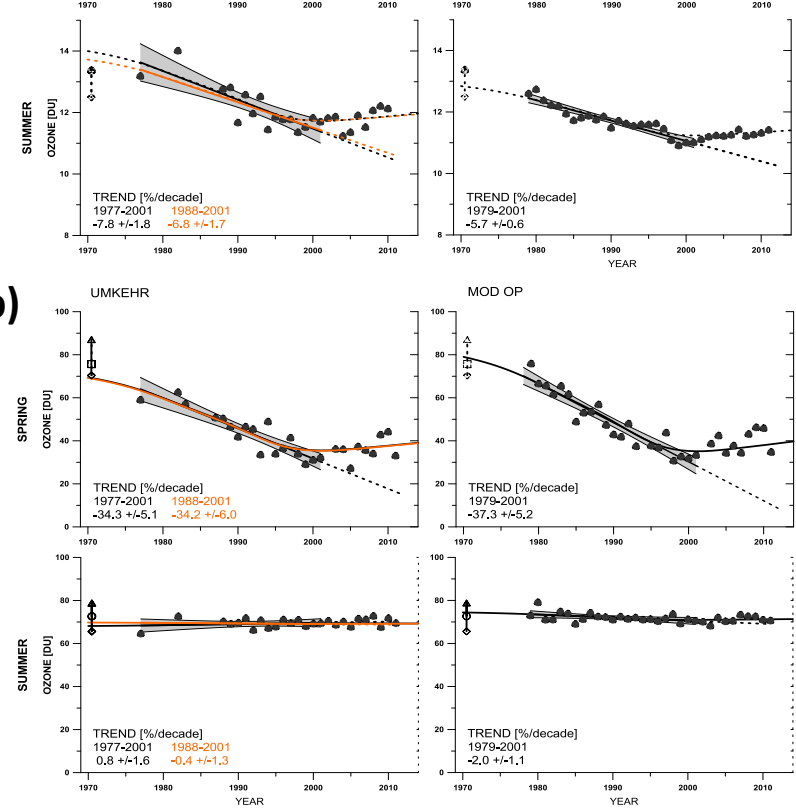

MOD OP
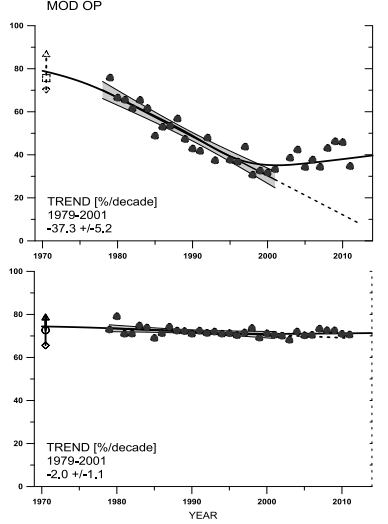

Fig. 7. Time series of ozone averaged over austral spring (September-November, top row) and summer (January-March, bottom row). Ozone is derived from the ground-based Dobson (left side) and satellite SBUV V8.6MOD measurements selected as overpasses the Syowa station (right side). Results are presented for combined Umkehr layers 8, 9 and 10 (a) and 4 (b). The averages are calculated after removing the dynamically driven variability as described in the text. The individual averages are displayed as grey points, the linear trends extend from 2001 to 2012 as dotted lines, and the high latitude EESC (Polar 2)-fitted trend as solid lines. The envelope represents the $95 \%$ confidence level prior to 2001 . The three symbols on the left side of the plot represent 1957-1972averaged ozone from three stations, Faraday $\left(65^{\circ} \mathrm{S}\right)$, King Baudouin $\left(70^{\circ} \mathrm{S}\right)$, and Halley $\left(73.5^{\circ} \mathrm{S}\right)$ as an indication of earlier values.

vertical and temporal patterns in correlation between proxies and ozone. This difference should be taken into account when analyzing the entire data set for correlations. It suggests that the reduction in variance analysis could be a more responsive approach for attributions that tend to vary with the stage of the solar activity.

\section{Discussion}

To analyze long-term changes in the ozone record at the Syowa station we need to understand the variability contributed by mechanisms other than chemical processes re- lated to the ODS concentrations in the stratosphere. After analyzing explanatory parameters that were included in the model (described at the end of Sect. 4.2), we determined that only a certain set of proxies was required to produce the best fit (the smallest residuals) for each layer and separately for summer and spring data analyses. The best set of proxies was selected based on the reduction of variance in the residuals of the model fit to ozone time series in 10 Umkehr layers (see Sect. 3.6 and Table 3 for discussion of proxy selection). We found that separation of data analysis into spring and summer helped to refine the set of proxies appropriate for each season.

\subsection{Long-term ozone trend}

In this section, we examine the fit of a long-term trend model to Syowa ozone data time series separated into spring and summer time series. Figure 7 shows long-term variations of ozone amount in spring and summer seasons. Results are shown for ozone changes in combined layer 8, 9 and 10 (above $4 \mathrm{hPa}$ or $40 \mathrm{~km}$ ) and layer $4(64-32 \mathrm{hPa}$ or $\sim 20$ $25 \mathrm{~km}$ ), which represent upper and middle stratospheric layers respectively. The left panels in Fig. 7a show year-to-year variability and the long-term changes of the upper stratospheric ozone (combined layers 8, 9 and 10) in the spring and summer seasons. Symbols in plots (black circles) display the evolution of austral spring (upper panels) and summer (lower panel) averages spanning three decades of observation. The interannual variability in data is reduced based on the fit of the statistical model (1), i.e. Model 2.2 and Model 3.3 are used to obtain statistical fit for ozone time series in combined layers 8,9 and 10 (panel a) and layer 4 (panel b) respectively. See Table 3 for information on the Model parameters. Prior to the beginning of systematic measurements at Syowa, Umkehr measurements were collected in the Antarctic region for several years at Faraday $\left(65.0^{\circ} \mathrm{S}\right)$, King Baudouin $\left(70.0^{\circ} \mathrm{S}\right)$ and Halley $\left(73.5^{\circ} \mathrm{S}\right)$ stations. Symbols shown on the left side of the plot in Fig. 7 provide the reference seasonal ozone value averaged from 1957 to 1972 that is representative of the "pre-ozone hole" levels over Antarctica. A reasonable agreement (within the uncertainties, shown as vertical bars) is found for seasonal ozone averages measured at the three historical Antarctic stations and the Syowa station.

The black curve shows the EESC (Polar 2) fit representative of effective stratospheric chlorine load at high latitude, and thick dashed lines show linear trends from 1977 to 2001. The shaded area shows $95 \%$ confidence level of the fit. The year 2001 is the inflection point in the time series. It relates the reverse in the ozone depletion to the 2001 maximum in the EESC Polar 2 curve (as discussed above). It is noticeable that Umkehr data sampling is fairly sparse in the record prior to 1988. In order to test how the time range of the data affects the trend analysis we also show results for the Umkehr data linear fit derived between 1988 and 2001. The red line 
a)
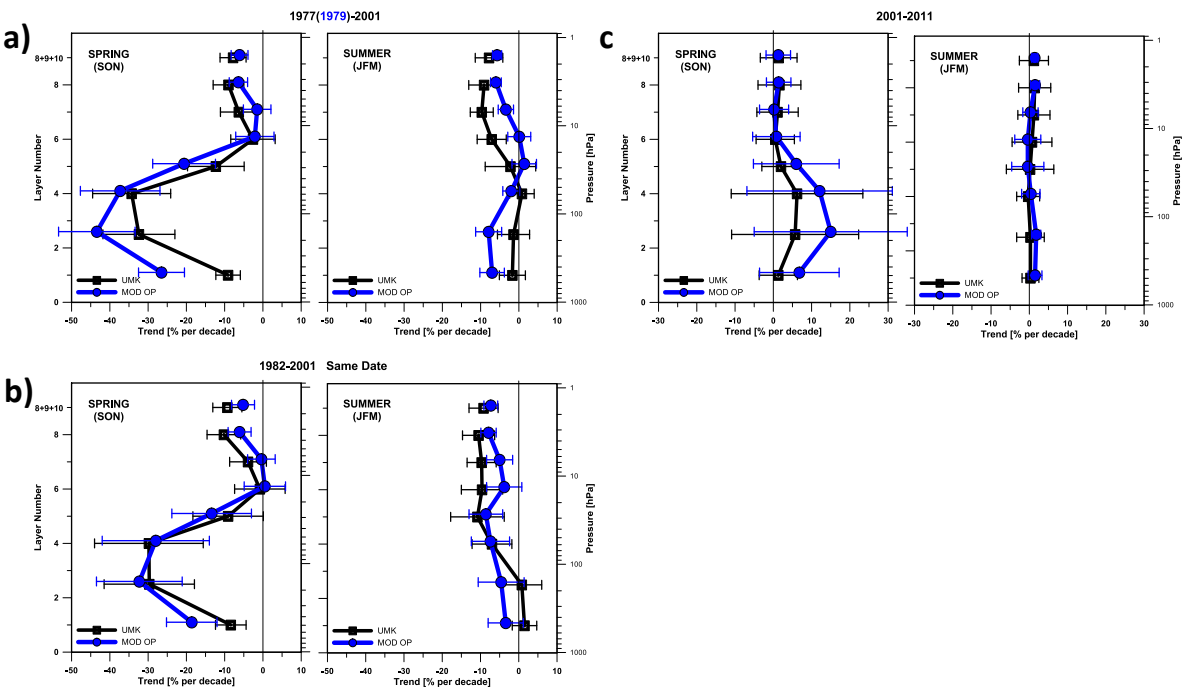

Fig. 8. The percent change in the vertical profile in Umkehr layers over the Syowa station as function of time (percent per decade) is displayed, after the removal of explainable variability as described in the text for both Umkehr and MOD OP. The ozone trends are shown in three panels of two plots, with spring (September-November) on the left, and summer (January-March). The linear trend is shown with the $95 \%$ confidence level bars. Panel (a) shows the trends from the late 1970s to 2001. Panel (b) shows the trends from 1982 to 2001, but using only days that have both Umkehr and MOD OP data. Panel (c) shows the trends of 2001-2012 fitted with EESC (Polar 2) curves.

in the upper left panel in Fig. 7a shows that the trend derived from the shorter time series is slightly increased in spring and reduced in summer as compared to the black line (1977-2001 fit). However, the change in the trend fit is not statistically significant, which is determined by the uncertainty of the fit (both lines are within grey area). The effect of the time range on the trend in Umkehr data is summarized in Table 4. The reduction of the time range does not affect results at lower altitudes, while at higher altitudes trends are increased. The uncertainty of the trend fit is increased when shorter a time range is used. It is possible that including measurements in the late 1970s and early 1980s adds more information for solar cycle fit and thus improves the trend analysis. Results of trend analysis for all layers are also summarized in Fig. 8 (discussed below).

Results of the long-term trend analyses of the Umkehr and MOD OP time series of ozone in the upper stratosphere are compared in Fig. 7a (left and right panels respectively). We find that analysis of the Umkehr and MOD OP ozone records in combined layers 8, 9 and 10 during the first half of the record (prior to 2002) shows a linear ozone decrease in the spring (-7.8 and $-6.1 \%$ decade $^{-1}$ respectively) and summer $\left(-7.8\right.$ and $-5.7 \%$ decade $\left.^{-1}\right)$. It is noticed that Umkehr and MOD OP-based trends agree within the uncertainties of the fit. Sparseness and higher variability in the Umkehr data could be partially responsible for the less perfect agreement between two data sets. In addition, DeLand et al. (2012) note that diurnal ozone changes in the upper stratosphere (2-8\%) may not be completely accounted for when the time series of ozone measurements from different satellites are combined to create MOD OP time series (Boyd et al., 2007; Haefele et al., 2008). Due to drifting orbits of the NOAA satellites, the local time of each satellite overpass over the ground-based station slowly shifts from the morning to the afternoon. It effectively causes the ozone to be measured during different periods of the diurnal cycle. As significant diurnal changes occur in the stratospheric ozone, it can add a drift to the satellite-measured ozone value from the beginning to the end of a single satellite record. Analysis and correction for the diurnal ozone changes need further investigation.

Ozone trends are also assessed in layer 4 (between 63 and $32 \mathrm{hPa}$ pressure levels) where levels of ozone depletion are strongly affected by heterogeneous chemical processes. The long-term variability in monthly and seasonal averages of Umkehr-derived ozone in layer 4 (middle stratosphere, maximum ozone layer) during spring and summer are shown in the upper and lower panels of Fig. 7b. The long-term ozone time series is found to decrease rapidly in the first half of the Umkehr and MOD OP records (shown in the right panel), while both data sets show a much different trend in the second half of the record. The seasonally separated long-term trends show the strongest decrease in lower stratospheric ozone in the springtime during the first half of the record $\left(-34.3\right.$ and $-37.3 \%$ decade $\left.^{-1}\right)$ and show little change, appearing rather flat, in the second half of the record. In contrast, summertime ozone does not show any significant longterm changes in either the first or second half of the record. These features agree with changes observed in the total ozone column record (WMO, 2007). As discussed in Salby et al. (2012), total ozone record at the South Pole shows strong coherence with planetary wave forcing, which is consistent 
Table 4. Calculated ozone trend from Umkehr at Syowa*. The trends are derived by the statistical model that includes the EESC (Polar 2) fit for the period 1977-2011. An asterisk symbol indicates the $95 \%$ significance of the trend. The pressure value is atmospheric pressure at the bottom of the Umkehr layer.

\begin{tabular}{|c|c|c|c|c|c|}
\hline \multirow[b]{3}{*}{ Layer } & \multicolumn{5}{|c|}{ 1977-2001 } \\
\hline & \multirow{2}{*}{$\begin{array}{r}\text { Pressure } \\
(\mathrm{hPa})\end{array}$} & \multicolumn{2}{|c|}{ Spring } & \multicolumn{2}{|c|}{ Summer } \\
\hline & & $\%$ decade $^{-1}$ & $95 \%$ CONFI & $\%$ decade $^{-1}$ & $95 \%$ CONFI \\
\hline 1 & 1000 & $-9.1^{*}$ & 1.6 & -1.7 & 1.7 \\
\hline 2 and 3 & 250 & $-32.4^{*}$ & 4.7 & -1.4 & 2.1 \\
\hline 4 & 62.5 & $-34.3^{*}$ & 5.1 & 0.8 & 1.6 \\
\hline 5 & 31.2 & $-12.3^{*}$ & 3.7 & -2.2 & 3.3 \\
\hline 6 & 15.6 & -2.6 & 2.9 & $-7.1^{*}$ & 1.9 \\
\hline 7 & 7.8 & $-6.3^{*}$ & 2.4 & $-9.7^{*}$ & 1.5 \\
\hline 8 & 3.9 & $-9.0^{*}$ & 2.0 & $-9.1^{*}$ & 2.0 \\
\hline \multirow[t]{2}{*}{8,9 and 10} & 3.9 & $-7.8^{*}$ & 1.7 & $-7.8^{*}$ & 1.8 \\
\hline & \multicolumn{5}{|c|}{$1988-2001$} \\
\hline 1 & 1000 & $-9.2^{*}$ & 2.0 & 0.0 & 1.0 \\
\hline 2 and 3 & 250 & $-32.7^{*}$ & 5.7 & 0.5 & 1.5 \\
\hline 4 & 62.5 & $-34.2^{*}$ & 6.0 & -0.4 & 1.3 \\
\hline 5 & 31.2 & $-12.6^{*}$ & 4.7 & $-7.9^{*}$ & 2.2 \\
\hline 6 & 15.6 & $-4.5^{*}$ & 3.6 & $-10.5^{*}$ & 1.4 \\
\hline 7 & 7.8 & $-8.1^{*}$ & 3.0 & $-10.0^{*}$ & 1.6 \\
\hline 8 & 3.9 & $-10.3^{*}$ & 2.5 & $-8.1^{*}$ & 1.8 \\
\hline \multirow[t]{2}{*}{8,9 and 10} & 3.9 & $-9.2^{*}$ & 2.2 & $-6.8^{*}$ & 1.7 \\
\hline & \multicolumn{5}{|c|}{$2001-2011$} \\
\hline 1 & 1000 & 1.3 & 2.5 & 0.3 & 1.1 \\
\hline 2 and 3 & 250 & 5.7 & 8.3 & 0.3 & 1.8 \\
\hline 4 & 62.5 & 6.2 & 8.6 & -0.3 & 1.5 \\
\hline 5 & 31.2 & 2.0 & 2.5 & 0.2 & 3.1 \\
\hline 6 & 15.6 & 0.5 & 2.5 & 0.7 & 2.6 \\
\hline 7 & 7.8 & 1.1 & 2.7 & 1.2 & 2.1 \\
\hline 8 & 3.9 & 1.6 & 2.8 & 1.4 & 2.1 \\
\hline 8,9 and 10 & 3.9 & 1.4 & 2.4 & 1.2 & 1.9 \\
\hline
\end{tabular}

with a similar coherence of springtime temperature, which modulates polar stratospheric cloud (PSC) formation.

The difference in the magnitude of ozone trends between the upper and the lower left panels in the middle stratosphere is clearly seen in Fig. 7. The mechanisms that influence trends derived in the middle stratosphere (Fig. 7b) are well studied (Solomon et al., 1999; Fioletov and Shepherd, 2005). The linear trends derived in the upper stratosphere are found to be less different between spring (left upper panel) and the summer (left bottom panel) in Fig. 7a. This indicates that different processes appear to affect long-term variability in the middle and upper stratosphere.

The Umkehr record at the Syowa station has several gaps in data collection. The earliest data are available in 1977, and then during 1982-1983. The systematic collection of
Umkehr Dobson data did not start until 1987-1988. Since the 1988-2001 period in the Umkehr record is slightly longer than one solar cycle we tested robustness of the 1988-2001 trend by using two additional time periods, such as 19772001, and 1982-2001. In addition, Umkehr data selection was also restricted to the $24 \mathrm{~h}$ matching criteria with the SBUV satellite overpass event. Figure 8 shows a summary of the derived trends as a function of altitude (or layer). Panel (a) exhibits comparison of trends derived from all available data in the Umkehr (black) and SBUV (blue) time series during the period 1977-2001. The left panel shows results for spring and the right panel summarizes summer trends. The error bars (95\% uncertainty) are provided for each layer. It is clear that the trends are not considered as statistically different if their uncertainties overlap. It is true 
for most of the layers, except for layer 1, where SBUV predicts a significantly smaller trend as compared to Umkehr, though the differences in the summer are nearly significant. Panel (b) shows a comparison for trends derived from a subset of Umkehr and SBUV data that are both restricted to a $24 \mathrm{~h}$ period during the satellite overpass (i.e., SBUV data are not selected whenever Umkehr is not available within $24 \mathrm{~h}$ of the station overpass). After applying the sampling restrictions, SBUV trends are reduced in layers 5 and below, which brings results in closer agreement with trends derived from Umkehr data in both spring and summer. However, it also raises the question if the limited sampling in Umkehr measurements affects Umkehr-derived ozone trends. In order to apply temporal matches, the MOD OP and Umkehr data have to be limited to the 1982-2001 time series. It changed summer ozone Umkehr and SBUV trends to become more negative in layers 4 and 5. It also suggests that loss of the 1970s data might be a cause for trend changes.

The changes in ozone after 2001 are plotted in panel (c) of Fig. 8. It becomes clear that the variability of the last 10 years of both Umkehr and MOD OP data prevents the trend model from clearly identifying any significant changes in the upper and lower stratosphere. The sampling differences of the MOD OP and Umkehr data is the most likely cause for difference in the derived trends in layers 4, 2, 3 and 1 for spring data analysis. The summer trends are all close to zero. Therefore, it is clear that no ozone recovery has been identified in the upper stratosphere (above layer 7), whereas ozone changes in the lower stratosphere (layers 4, 2 and 3) in spring indicate a positive trend, although statistically nonsignificant.

The ozone trend for each Umkehr layer derived from the Syowa record is summarized in Table 4 . There are only 41 data profiles available at the Syowa station during the 19771988 time period, so we investigate impact on the fit if these data are excluded. Based on analysis of results presented in Table 4, we find that difference in derived trends based on two periods is insignificant. However, the uncertainties of the trend are increased when a shorter period of time is used for trend analysis, and becomes more robust when time series are extended to include these infrequent but very important data. Therefore, it is suggested to use the 1977-2001 time period for Umkehr ozone trend analysis.

\subsection{CUSUM analysis}

The CUSUM of Umkehr and SBUV time series ozone residuals can be used for systematic assessment of the change in the trend (Newchurch et al., 2003; Yang et al., 2006). The panels in Fig. 9a and $b$ show the CUSUM in the spring and summer seasons. The CUSUM of residuals assesses the agreement between the tendency observed in the data and the predictions of the two Goddard-modeled EESC curves (Polar $2-5.5$ years of mean age of air, and Polar $3-10$ years of mean age of air) that represent the rate of the ODS-
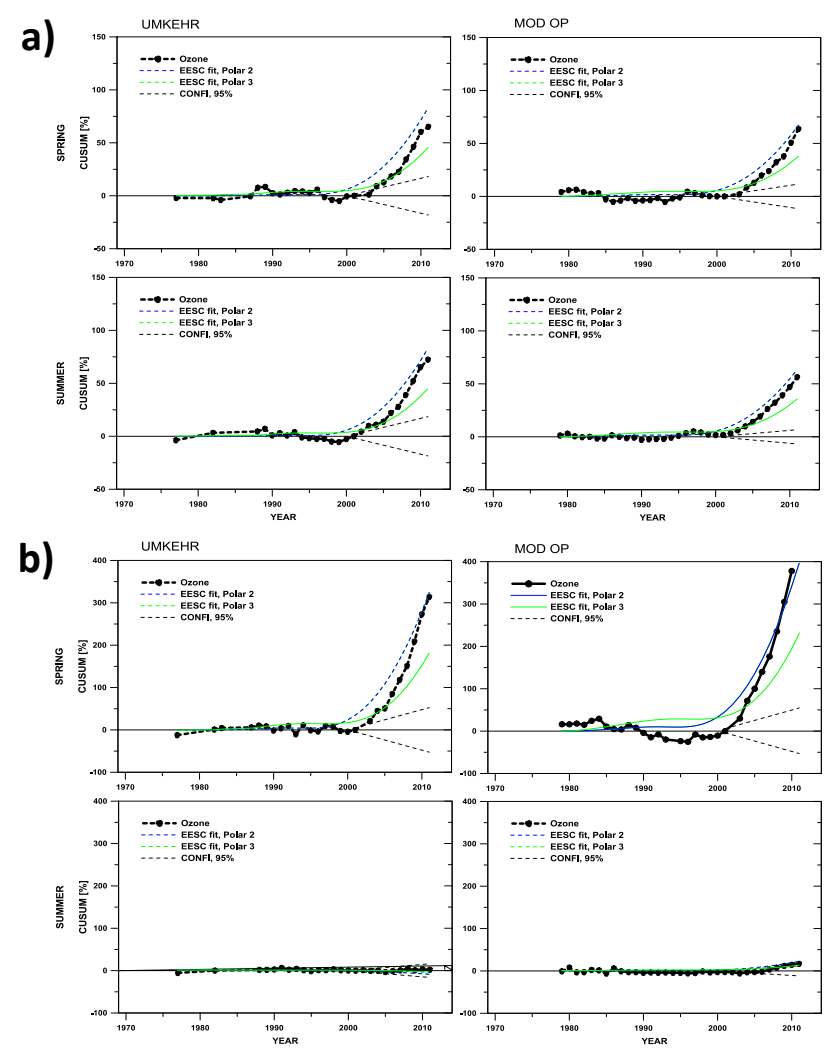

Fig. 9. CUSUM analysis of Umkehr (left side) and MOD OP (right side) are displayed in panels (a) (combined layers 8, 9 and 10) and (b) (layer 4). Cumulative residuals are plotted as black dots. The Polar 2 (blue) and Polar 3 (green) EESC curves are also shown for comparisons. Note: year 2002 was removed from the analysis based on the unusual dynamical conditions of that year. Upper (bottom) row in each panel represents analysis of 3-month averages for spring (summer). The broken lines show the $95 \%$ confidence level.

related ozone destruction and recovery as function of time. The CUSUM method helps to compare the rate of ozone recovery with two curves. We have separated the assessment of trend results to spring and summer. A linear trend is calculated from the time series of residuals of the statistical model (includes all but EESC proxies) fit into ozone data selected between 1977 and 2001. The statistical trend model contains only proxies that significantly improve the fit (discussed above).

The linear fit is then extended after 2001, and the departure of the residual data from the linear fit is plotted as cumulative change in ozone levels relative to the predicted ozone depletion after 2001. Sequential integration of the residual of the fit after 2001 smooths out the variability in the data and helps to assess whether the change in the data follows the slope of the Polar 2 or Polar 3 EESC curves. An envelope of the $95 \%$ confidence level is shown. The change from the linear forecast is therefore clearly detectable. 
Comparison of ozone residuals (CUSUM method) with the two sets of EESC curves is shown in Fig. 9. The large positive anomaly of 2002 affected by the split of the vortex had interfered in CUSUM analysis since the infliction point in the Polar 2 curve had been just the year prior to 2002 and thus the CUSUM was pushed to very high values right away. Therefore, the CUSUMs started "outside" of the confidence interval right away. We removed 2002 data to eliminate large residuals around 2001. These changes shifted the residuals closer to the Polar 3 curve (green line), at the beginning of 2002-2010 period. The Polar 3 curve has a maximum in 2008 and the CUSUM shows a closer fit to the Polar 3 curve prior to 2006. However, after 2006, the CUSUM curve gradually starts to approach the Polar 2 curve (blue line). Results agree for the SBUV (right) and Umkehr (left panel) upper stratospheric ozone analysis. The cumulative residuals of ozone in the upper stratosphere do not seem to follow the either the Polar 2 or Polar 3 curves after 2001. From the CUSUM analysis of ozone residuals in layer 8 during both spring and summer seasons, it appears that the turning point in the ozone time series could be positioned a few years after 2001, but before 2008. Also, the rate of ozone changes after 2001 is faster than predicted by the Polar 2 curve. Therefore, the currently used predictions for the EESC curve for the polar stratosphere should be re-evaluated to improve ozone recovery analysis over Antarctica.

Conversely, in layer 4 , systematic positive CUSUM is found after the turning point in 2001 in annual mean and the spring season data (Fig. 9b). The CUSUM for spring data analysis is found above a $95 \%$ confidence level, and eventually shows agreement with the Polar 2 curve. The increase in the CUSUM for the summer season is very slow and remains within the confidence limits until 2011. It appears that after 2005 both Umkehr and SBUV OP CUSUM analyses of ozone data in layer 4 selected during the spring season show a fairly good agreement with the ozone recovery rate predicted by the Polar 2 curve (blue).

\subsection{Ozone recovery delay and EESC curves}

Since no direct EESC measurements for the Antarctica stratosphere extend over the period of Syowa measurements, we rely on the modeled estimates of ozone depleting substances (EESC data) to evaluate changes in the Syowa Umkehr ozone time series. The long-term trend of ozone at the Syowa station in the lower stratosphere is found to be in agreement with the expected trend based on EESC Polar 2. However, in the upper stratosphere, the recent ozone changes appear to indicate that ozone recovery follows the ODS decline with rates slower that defined by the EESC Polar 2 curve, but faster than predicted by the Polar 3 curve. These results could imply an age of air longer than 5.5 years for the upper stratosphere over Antarctica and longer ODS transit time from the source regions. Although apparent age of air ( 10 years) can be derived from the MIPAS SF6 strato- spheric measurements over Antarctica, it is most likely affected by descent of mesospheric SF6-depleted air masses, and thus cannot be used to estimate distribution of stratospheric ODS concentrations (or EESC curve) at polar regions (Ray et al., 2010; Garcia et al., 2011; Hall et al., 2011; Stiller et al., 2012). However, recently published papers (Laube et al., 2013; Rigby et al., 2013) reassessed the stratospheric lifetime of many halogens regulated by the Montreal Protocol and estimated a somewhat longer lifetime for major ODSs, such as CFC-11, CFC-12 and CH3CCl3. The nonlinear relationship between the age of air and fractional release rates (FRR) complicates the assessment and prediction of the EESC concentrations. The authors of both papers found the age of air to be longer than those published by Newman et al. (2006) and the ozone assessment (2011), which in turn would affect the EESC curves. Since the behavior of ozone in upper stratosphere over the Syowa station agree less closely with the Polar 2 curve and more closely with Polar 3 curve, it means that the age of air in the upper stratosphere over Syowa most likely corresponds to an age of air longer than 5.5 years suggested by the $2010 \mathrm{WMO}$ ozone assessment for the polar regions. However, both papers emphasize that the FRR and age-of-air correlations are done under the assumption of the steady state of the stratospheric transport. Since transport is expected to change in the future according to climate change scenarios (acceleration of the Brewer-Dobson circulation, more wave breaking in stratosphere, recirculation, etc.), the concentrations of the ODS in the stratosphere would also be expected to change over time (e.g., Neu and Plumb, 1999; Ray et al., 2010).

We view the Syowa data time series as a way to assess the appropriateness of using various EESC curves in prediction of ozone recovery in the polar stratospheric regions.

Yet another possible explanation for delay in stratospheric ozone recovery over Syowa is that while the increase in greenhouse gases has raised surface temperatures, the stratosphere has cooled, an effect amplified in the Antarctic by the reduction of ozone by ODS and increase in water vapor and carbon dioxide concentrations, and resultant changes in the radiative absorption balance (Thompson et al., 2011). Temperatures in the upper and middle stratosphere at midlatitudes have remained constant since the middle of 1990s (WMO, 2007; Steinbrecht et al., 2009). According to Hassler et al. (2011), the change of the dynamics of the Antarctic stratosphere has affected ozone reduction at the Antarctic Syowa station.

\section{Conclusions}

We have investigated the long-term ozone trend in the stratosphere over the Antarctic using reprocessed Umkehr data. Our research is based on Umkehr observations from Dobson ozone spectrophotometers that are of the high quality required for detection of significant ozone change (recovery) 
in relation to the decrease in the ODS concentrations. The long-term variability and trend observed in Umkehr ozone profile data is in good agreement with that seen in the SBUV V8.6 merged ozone data set (see Sect. 3.2 for details). Several explanatory variables (proxies) are utilized in a statistical model to remove effects of quantifiable atmospheric parameters related to interannual and dynamically driven long-term ozone changes, such that the trends related to the ODS levels in the stratosphere can be examined. We also verified that part of the long-term ozone changes over Syowa are associated with the changes in the polar vortex position and persistence relative to the geophysical location of the Syowa station, and that this effect can be attributed in the statistical model using equivalent latitude data at corresponding atmospheric pressure levels. We verified the appropriateness of using EqLat at $850 \mathrm{~K}$ as a proxy for the statistical trend model by assessing correlations of stratospheric ozone with daily EqLat time series derived for Syowa at several atmospheric levels $(520 \mathrm{~K}, 850 \mathrm{~K}, 1300 \mathrm{~K})$.

Here are some conclusions from working on the Syowa data set analysis.

1. The data sampling in some ground-based systems (i.e., Umkehr) can be a limiting factor for trend analysis. We find an improvement in correlation between monthly averaged ozone and a proxy (i.e EqLat) after the proxy's daily time series is limited to the dates of the ground-based measurement (correlation is lower when monthly average for the proxy includes all days of the month). This is critical for analysis of data at stations where variability is very high, such as in spring at Syowa.

2. The reduction in the residual variance of a model fit can be marginal, which makes the method of finding the best lag estimate less robust.

3. Ideally, there should be a physical mechanism connecting the variability in each proxy to variability in ozone. In our analysis, the mechanism for correlation of ENSO with the variability in upper stratospheric ozone is unknown. However the literature includes references that relate effects of ENSO to ozone in the tropical middle and lower stratosphere (Randel et al., 2009, Calvo et al., 2010); since the tropics are connected to the polar regions via the Brewer-Dobson circulation, we therefore expect ozone in the polar stratosphere be correlated with the ENSO variability. Since ENSO is correlated to ozone in the lower/middle stratosphere, to the extent that ozone in the middle/lower stratosphere is correlated to that in the upper stratosphere, then ENSO should be correlated to ozone in the upper stratosphere. The marginal reduction in variability from some proxies (point 2) makes identifying a physical mechanism (point 3) critical for selecting explanatory parameters for the best model fit.
4. The EqLat proxy is useful, since it helps to separate the chemical and dynamical source in ozone variability. However, it does not explain the specific physical mechanisms influencing the dynamical variability of the atmosphere, and hence the vortex over Syowa.

5. The EqLat proxy is likely related to SAM, ENSO and other dynamical proxies, although the detailed mechanisms are not obvious, high correlation of EqLat to ozone variability in the polar region was found at Syowa.

6. An enhancement of the correlation between ozone and the SAM index was seen in years with the high solar activity, when correlation in layers $5-10$ is significantly enhanced as compared to the low solar activity years.

The middle stratospheric ozone trend at Syowa closely follows the pattern suggested by the Polar 2 EESC curve that is currently recommended in the ozone assessment (2010) for analysis of data in the polar regions (5.5 years). However, at the higher altitudes (pressures lower than $4 \mathrm{hPa}$ ) ozone recovery in the Syowa data appears to be delayed (see Figs. 7a and 9a). Ozone in the upper stratosphere may be affected by a longer transport time; a better fit to Syowa observed ozone variability in the upper stratosphere is obtained using the EESC curve associated with a somewhat older age of air (between 6 and 10 years). Results of the analysis presented in this paper suggest that Syowa's ozone record in the upper stratosphere has not yet reached the second stage of ozone recovery (WMO, 2007; Yang et al., 2008). The Syowa record indicates a statistically significant decrease between 1977 and 2001; after 2000, however, the stratospheric ozone record remains essentially flat even after the increase of the ODS concentrations has stopped (WMO, 2011). This leveling off of the ozone values in the last ten years suggests continuing ozone destruction may be related to continuous changes in the BDC-related transport. A recent paper (Stiller et al., 2012) analyzed the MIPAS satellite $\mathrm{SF}_{6}$ data for changes in the age of air. Results suggest a reduction in the strong gradient in the age of air along the edge of the stratospheric polar vorticities, which is consistent with an intensification of the BDC and a weakening of the subtropical and polar mixing barriers. The authors found that the changes in the age of air during the 2002-2010 time periods vary between Northern and Southern Hemispheres, as well as between middle-, tropical- and high-latitude regions. The findings of that paper point to differences between lower-, middle- and upper-stratospheric transport processes. For the southern polar upper stratosphere, Stiller et al. (2012) find a positive linear increase in the age of air that is larger than that published by Engel et al. (2009). Further analysis of the processes that could affect the MIPAS $\mathrm{SF}_{6}$ results are needed in order to understand the dynamical and photochemical processes that affect ozone in the polar 
upper stratosphere in the winter season. Another important process that can contribute to ozone variability in the upper stratosphere is the solar flux cycle. Several publications in recent years described potential changes observed in the UV and visible solar flux spectra when transitioning between the maximum and the minimum stages in the solar cycle and associated effects on stratospheric temperature and photochemical processes (Haigh et al., 2010, Oberländer et al., 2012). These papers indicate the importance of understanding the long-term changes in photochemical processes that lead to the production of stratospheric ozone (Haigh et al., 2010). The last solar cycle maximum was observed in 20002002, and the sun's activity declined until December 2009. This longer than usual minimum of the solar cycle could be one factor contributing to the delay in ozone recovery in the upper stratosphere where photochemical processes dominate over dynamical processes. The upper stratospheric ozone depletion arising from solar cycle variations is enhanced from 0.7 to $1.2 \%$ when the spectral changes of the solar cycle are taken into account (Haigh et al., 2010). Upper stratospheric ozone depletion (layer $8,4 \mathrm{hPa}$ ) prior to 2001 is estimated at $\sim 1.2 \%$ per year (Table 4). For the 2001-2011 time period, a small positive ozone trend is found only $\sim 0.2 \%$ per year or about $1 \%$ over 5 years as compared to a $0.7 \%$ change in ozone due to the solar cycle spectrum proposed in the abovereferenced paper. With the continuation of observations of ozone over the southern polar regions, it will be possible to determine which processes play the most important role and how the climate changes will affect ozone in the future.

\section{Supplementary material related to this article is available online at http://www.atmos-chem-phys.net/14/ 3945/2014/acp-14-3945-2014-supplement.pdf.}

Acknowledgements. We would like to thank E. Beach of NOAA/NESDIS regarding the analysis of satellite data and C. Kobayashi of the Meteorological Research Institute and T. Sakurai of Ozone Layer Monitoring Office, Japan Meteorological Agency, regarding the analysis of Umkehr observation. We also thank the anonymous reviewers for the comments and suggestions, which significantly contributed to improving the quality of the publication. In addition, we thank the members of the Japanese Antarctic Research Expedition for the continuous long-term ozone field observations. Work at the Jet Propulsion Laboratory, California Institute of Technology, was done under contract with the National Aeronautics and Space Administration. The authors would like to thank S. M. Hollandsworth Frith (NASA/Goddard) and M. T. DeLand (Science Systems and Applications, Inc.) for help with interpretation of the SBUV V8.6 MOD data with regards to stratospheric ozone variability and long-term changes over Syowa station.

Edited by: C. von Savigny

\section{References}

Appenzeller, C., Weiss, A. K., and Staehelin, J.: North Atlantic oscillation modulates total ozone winter trends, Geophys. Res. Lett., 27, 1131-1134, 2000.

Aquila, V., Oman, L. D., Stolarski, R. S., Colarco, P. R., and Newman, P. A.: Dispersion of the volcanic sulfate cloud from a Mount Pinatubo-like eruption, J. Geophys. Res., 117, D06216, doi:10.1029/2011JD016968, 2012.

Aquila, V., Oman, L. D., Stolarski, R., Douglass, A. R., and Newman, P. A.: The Response of Ozone and Nitrogen Dioxide to the Eruption of Mt. Pinatubo at Southern and Northern Midlatitudes, J. Atmos. Sci., 70, 894-900, doi:10.1175/JAS-D-120143.1, 2013.

Arblaster, J. M. and Meehl, G. A.: Contributions of external forcings to southern annular mode trends, J. Climate, 19, 2896-2905, 2006.

Baldwin, M. P., Gray, L. J., Dunkerton, T. J., Hamilton, K. , Haynes, P. H., Randel, W. J., Holton, J. R., Alexander, M. J., Hirota, I., Horinouchi, T., Jones, D. B. A., Kinnersley, J. S., Marquardt, C., Sato, K., and Takahashi, M.: The quasi-biennial oscillation, Rev. Geophys., 39, 179-229, 2001.

Bhartia, P. K., McPeters, R. D., Flynn, L. E., Taylor, S., Kramarova, N. A., Frith, S., Fisher, B., and DeLand, M.: Solar Backscatter UV (SBUV) total ozone and profile algorithm, Atmos. Meas. Tech., 6, 2533-2548, doi:10.5194/amt-6-2533-2013, 2013.

Boyd, I. S., Parrish, A. D., Froidevaux, L., von Clarmann, T., Kyrölä, E., Russell III, J. M., and Zawodny, J. M.: Groundbased microwave ozone radiometer measurements, compared with Aura-MLS v2.2 and other instruments at two Network for Detection of Atmospheric Composition Change sites, J. Geophys. Res., 112, D24S33, doi:10.1029/2007JD008720, 2007.

Calvo, N., Garcia, R. R., Randel, W. J., and Marsh, D.: Dynamical mechanism for the increase in tropical upwelling in the lowermost tropical stratosphere during warm ENSO events, J. Atmos. Sci., 67, 2331-2340, 2010.

DeLand, M. T., Taylor, S. L., Huang, L. K., and Fisher, B. L.: Calibration of the SBUV version 8.6 ozone data product, Atmos. Meas. Tech., 5, 2951-2967, doi:10.5194/amt-5-2951-2012, 2012.

Diaz, H. F. and Markgraf, V.: El Niño: Historical and Paleoclimatic Aspects of the Southern Oscillation, Cambridge University Press, 476 pp., 1992.

Douglass, A. R., Stolarski, R. S., Strahan, S. E., and Polansky, B. C.: Sensitivity of Arctic ozone loss to polar stratospheric cloud volume and chlorine and bromine loading in a chemistry and transport model, Geophys. Res. Lett., 33, L17809, doi:10.1029/2006GL026492, 2006.

Douglass, A. R., Stolarski, R. S., Schoeberl, M. R., Jackman, C. H., Gupta, M. L., Newman, P. A., Nielsen, J. E., and Fleming, E. L.: Relationship of loss, mean age of air and the distribution of CFCs to stratospheric circulation and implications for atmospheric lifetimes, J. Geophys. Res., 113, D14309, doi:10.1029/2007JD009575, 2008.

Engel, A., Mobius, T., Bonisch, H., Schmidt, U., Heinz, R., Levin, I., Atlas, E., Aoki, S., Nakazawa, T., Sugawara, S., Moore, F., Hurst, D., Elkins, J., Schauffler, S., Andrews, A., and Berine, K.: Age of stratospheric air unchanged within uncertainties over the past 30 years, Nat. Geosci., 2, 28-31, doi:10.1038/ngeo388, 2009. 
Farman, J. C., Gardiner, B. G., and Shanklin, J. D.: Large losses of total ozone in Antarctica reveal seasonal $\mathrm{ClO}_{\mathrm{X}} / \mathrm{NO}_{\mathrm{x}}$ interaction, Nature, 315, 207-210, 1985.

Fioletov, V. E. and Shepherd, T. G.: Summertime total ozone variations over middle and polar latitudes, Geophys. Res. Lett., 32, L04807, doi:10.1029/2004GL022080, 2005.

Fioletov, V. E., Tarasick, D. W., and Petropavlovskikh, I.: Estimating ozone variability and instrument uncertainties from $\operatorname{SBUV}(/ 2)$, ozonesonde, Umkehr, and SAGE II measurements: Short-term variations, J. Geophys. Res., 111, D02305, doi:10.1029/2005JD006340, 2006.

Fogt, R. L. and Bromwich, D. H.: Decadal Variability of the ENSO Teleconnection to the High-Latitude South Pacific Governed by Coupling with the Southern Annular Mode, J. Climate, 19, 979997, 2006.

Fogt, R. L., Perlwitz, J., Pawson, S., and Olsen, M. A.: Intra-annual relationships between polar ozone and the SAM, Geophys. Res. Lett., 36, L04707, doi:10.1029/2008GL036627, 2009.

Fusco, A. C. and Salby, M. L.: Interannual variations of total ozone and their relationship to variations of planetary wave activity, J. Climate, 12, 1619-1629, 1999.

Garcia, R. R. and Randel, W. J.: Acceleration of the Brewer-Dobson Circulation due to Increases in Greenhouse Gases, J. Atmos. Sci., 65, 2731-2739, doi:10.1175/2008JAS2712.1, 2008.

Garcia, R. R., Randel, W. J., and Kinnison, D. E.: On the determination of age of air trends from atmospheric trace species, J. Atmos. Sci., 68, 139-154, 2011.

Garcia-Herrera, R., Calvo, N., Garcia, R. R., and Giorgetta, M. A.: Propagation of ENSO temperature signals into the middle atmosphere: A comparison of two general circulation models and ERA-40 reanalysis data, J. Geophys. Res., 111, D06101, doi:10.1029/2005JD006061, 2006.

Garfinkel, C. I. and Hartmann, D. L.: Effects of the El Niño - Southern Oscillation and the Quasi-Biennial Oscillation on polar temperatures in the stratosphere, J. Geophys. Res., 112, D19112, doi:10.1029/2007JD008481, 2007.

Götz, F. W. P., Meetham, A. R., and Dobson, G. M. B.: The vertical distribution of ozone in the atmosphere, Proc. R. Soc. Lon. Ser.A, 145, 416-443, 1934.

Haefele, A., Hocke, K., Kämpfer, N., Keckhut, P., Marchand, M., Bekki, S., Morel, B., Egorova, T., and Rozanov, E.: Diurnal changes in middle atmospheric $\mathrm{H}_{2} \mathrm{O}$ and $\mathrm{O}_{3}$ : Observations in the Alpine region and climate models, J. Geophys. Res., 113, D17303, doi:10.1029/2008JD009892, 2008.

Haigh, J. D. and Roscoe, H. K.: Solar influences on polar modes of variability, Meteorol. Z., 15, 371-378, 2006.

Haigh J. D., Winning, A. R., Toumi, R., and Harder, J. W.: An influence of solar spectral variations on radiative forcing of climate, Nature, 467, 696-699, 2010.

Hall, B. D., Dutton, G. S., Mondeel, D. J., Nance, J. D., Rigby, M., Butler, J. H., Moore, F. L., Hurst, D. F., and Elkins, J. W.: Improving measurements of $\mathrm{SF}_{6}$ for the study of atmospheric transport and emissions, Atmos. Meas. Tech., 4, 2441-2451, doi:10.5194/amt-4-2441-2011, 2011.

Hamilton, K.: Effects of an Imposed Quasi-Biennial Oscillation in a Comprehensive Troposphere-Stratosphere-Mesosphere General Circulation Model, J. Atmos. Sci., 55, 2393-2418, 1998.

Harnik, N., Perlwitz, J., and Shaw, T. A.: Observed Decadal Changes in Downward Wave Coupling between the Stratosphere and Troposphere in the Southern Hemisphere, J. Climate, 24, 4558-4569, 2011.

Hassler, B., Bodeker, G. E., Solomon, S., and Young, P. J.: Changes in the polar vortex: Effects on Antarctic total ozone observations at various stations, Geophys. Res. Lett., 38, L01805, doi:10.1029/2010GL045542, 2011.

Hendrick, F., Pommereau, J.-P., Goutail, F., Evans, R. D., Ionov, D., Pazmino, A., Kyrö, E., Held, G., Eriksen, P., Dorokhov, V., Gil, M., and Van Roozendael, M.: NDACC/SAOZ UV-visible total ozone measurements: improved retrieval and comparison with correlative ground-based and satellite observations, Atmos. Chem. Phys., 11, 5975-5995, doi:10.5194/acp-11-5975-2011, 2011.

Hitchman, M. H. and Rogal, M. J.: Seasonal and ENSO Influences of Tropical Convection on SH Ozone During the Winter to Spring Transition, American Geophysical Union, Fall Meeting 2010, San Francisco, California, 13-17 December, abstract\#A51B-0091, 2010.

Hoskins, B. J. and Karoly, D. J.: The steady linear response of a spherical atmosphere to thermal and orographic forcing, J. Atmos. Sci., 38, 1179-1196, 1981.

$\mathrm{Hu}, \mathrm{Y}$. and Fu, Q.: Stratospheric warming in Southern Hemisphere high latitudes since 1979, Atmos. Chem. Phys., 9, 4329-4340, doi:10.5194/acp-9-4329-2009, 2009.

Ialongo, I., Sofieva, V., Kalakoski, N., Tamminen, J., and Kyrölä, E.: Ozone zonal asymmetry and planetary wave characterization during Antarctic spring, Atmos. Chem. Phys., 12, 2603-2614, doi:10.5194/acp-12-2603-2012, 2012.

Jiang, X., Pawson, S., Camp, C. D., Nielsen, E., Shia, R., Liao, T., Jeev, K., Limpasuvan, V., and Yung, Y. L.: Interannual variability and trends in extratropical ozone. Part II: Southern hemisphere, J. Atmos. Sci., 65, 3030-3041, 2008.

Krzyścin, J. W. and Rajewska-Więch, B.: Trends in the ozone vertical distribution from the Umkehr observations at Belsk 1963-2007, Int. J. Remote Sens., 30, 3917-3926, doi:10.1080/01431160902821866, 2009.

Kuroda, Y. and Kodera, K.: Solar cycle modulation of the Southern Annular Mode, Geophys. Res. Lett., 32, L13802, doi:10.1029/2005GL022516, 2005.

Kuroda, Y. and Yamazaki, K.: Influence of the solar cycle and QBO modulation on the Southern Annular Mode, Geophys. Res. Lett., 37, L12703, doi:10.1029/2010GL043252, 2010.

Laube, J. C., Keil, A., Bönisch, H., Engel, A., Röckmann, T., Volk, C. M., and Sturges, W. T.: Observation-based assessment of stratospheric fractional release, lifetimes, and ozone depletion potentials of ten important source gases, Atmos. Chem. Phys., 13, 2779-2791, doi:10.5194/acp-13-2779-2013, 2013.

L'Heureux, M. L. and Thompson, D. W. J.: Observed relationships between the El Niño-Southern Oscillation and the extratropical zonal-mean circulation, J. Climate, 19, 276-287, 2006.

Li, F., Newman, P. A., and Stolarski, R. S.: Relationships between the Brewer-Dobson circulation and the southern annular mode during austral summer in coupled chemistryclimate model simulations, J. Geophys. Res., 115, D15106, doi:10.1029/2009JD012876, 2010.

Lu, H., Gray, L. J., Baldwin, M. P., and Jarvis M. J.: Life cycle of the QBO modulated 11-year solar cycle signals in the Northern Hemispheric winter, Q. J. Roy. Meteor. Soc., 135, 1030-1043, 2009. 
Lu, H., Jarvis, M. J., Gray, L. J., and Baldwin, M. P.: High- and lowfrequency 11-year solar cycle signatures in the Southern Hemispheric, Q. J. Roy. Meteor. Soc., 137, 1641-1656, 2011.

Mäder, J. A., Staehelin, J., Brunner, D., Stahel, W. A., Wohltmann, I., and Peter, T.: Statistical modeling of total ozone: Selection of appropriate explanatory variables, J. Geophys. Res., 112, D11108, doi:10.1029/2006JD007694, 2007.

Manney, G. L., Froidevaux, L., Waters, J. W., and Zurek, R. W.: Evolution of Microwave Limb Sounder ozone and the polar vortex during winter, J. Geophys. Res., 100, 2953-2972, 1995.

Manney, G. L., Michelsen, H. A., Santee, M. L., Gunson, M. R., Irion, F. W., Roche, A. E., and Livesey, N. J.: Polar vortex dynamics during spring and fall diagnosed using trace gas observations from the atmospheric trace molecule spectroscopy instrument, J. Geophys. Res., 104, 18841-18866, 1999.

Manney, G. L., Daffer, W. H., Zawodny, J. M., Bernath, P. F., Hoppel, K. W., Walker, K. A., Knosp, B. W., Boone, C., Remsberg, E. E., Santee, M. L., Harvey, V. L., Pawson, S., Jackson, D. R., Deaver, L., McElroy, C. T., McLinden, C. A., Drummond, J. R., Pumphrey, H. C., Lambert, A., Schwartz, M. J., Froidevaux, L., McLeod, S., Takacs, L. L., Suarez, M. J., Trepte, C. R., Cuddy, D. C., Livesey, N. J., Harwood, R. S., and Waters, J. W.: Solar occultation satellite data and derived meteorological products: Sampling issues and comparisons with Aura Microwave Limb Sounder, J. Geophys. Res., 112, D24S50, doi:10.1029/2007JD008709, 2007.

Marshall, G. J.: Trends in the Southern Annular Mode from observations and reanalyses. J. Climate, 16, 4134-4143, 2003.

McPeters, R. D., Labow, G. J., and Logan, J. A.: Ozone climatological profiles for satellite retrieval algorithms, J. Geophys. Res., 112, D05308, doi:10.1029/2005JD006823, 2007.

McPeters, R. D., Bhartia, P., and Flynn, L.: A 40 year time series of SBUV observations: the version 8.6 processing, Quadrennial Ozone Symposium 2012 Toronto, 27-31 August, ID5929, 2012.

Miyagawa, K.: Development of automated measuring system for Dobson ozone spectrophotometer, in XVIII Quadrennial Ozone Symposium, vol. 2, edited by: Bojkov, R. and Visconti, G., 951954, Int. Ozone Comm., L'Aquila, Italy, 1996.

Miyagawa, K. and Sasaki, T.: Vertical Ozone Profile by Umkehr Measurements at Syowa Station, Int. J. Remote Sens., 30, 40434053, 2009a.

Miyagawa, K., Sasaki, T., Nakane, H., Petropavlovskikh, I., and Evans, R. D.: Reevaluation of long-term Umkehr Data and Ozone profiles at Japanese stations, J. Geophys. Res., 114, D07108, doi:10.1029/2008JD010658, 2009b.

Molina, M. J. and Rowland, F. S.: Stratospheric sink for chlorofluoromethanes: Chlorine atom catalyzed destruction of ozone, Nature, 249, 810-812, 1974.

Neu, J. L. and Plumb, R. A.: The age of air in a "leaky pipe" model of stratospheric transport, J. Geophys. Res., 104, 19243-19225, 1999.

Newchurch, M. J., Yang, E. S., Cunnold, D. M., Reinsel, G. C., Zawodny, J. M., and Russell III, J. M.: Evidence for slowdown in stratospheric ozone loss: First stage of ozone recovery, J. Geophys. Res., 108, 4507, doi:10.1029/2003JD003471, 2003.

Newman, P. A., Nash, E. R., and Rosenfield, J. E.: What controls the temperature of the Arctic stratosphere during the spring?, J. Geophys. Res., 106, 19999-20010, 2001.
Newman, P. A., Nash, E. R., Kawa, S. R., Montzka, S. A., and Schauffler, S. M.: When will the Antarctic ozone hole recover?, Geophys. Res. Lett., 33, L12814, doi:10.1029/2005GL025232, 2006.

Newman, P. A., Daniel, J. S., Waugh, D. W., and Nash, E. R.: A new formulation of equivalent effective stratospheric chlorine (EESC), Atmos. Chem. Phys., 7, 4537-4552, doi:10.5194/acp7-4537-2007, 2007.

Oberländer, S., Langematz, U., Matthes, K., Kunze, M., Kubin, A., Harder, J., Krivova, N. A., Solanki, S. K., Pagaran, J., and Weber, M.: The influence of spectral solar irradiance data on stratospheric heating rates during the 11 year solar cycle, Geophys. Res. Lett., 39, L01801, doi:10.1029/2011GL049539, 2012.

Oman, L., Waugh, D. W., Pawson, S., Stolarski, R. S., and Newman, P. A.: On the influence of anthropogenic forcings on changes in the stratospheric mean age, J. Geophys. Res., 114, D03105, doi:10.1029/2008JD010378, 2009.

Oman, L. D., Waugh, D. W., Kawa, S. R., Stolarski, R. S., Douglass, A. R., and Newman, P. A.: Mechanisms and feedback causing changes in upper stratospheric ozone in the 21 st century, J. Geophys. Res., 115, D05303, doi:10.1029/2009JD012397, 2010.

Perlwitz, J. and Harnik, N.: Downward coupling between the stratosphere and troposphere: The relative roles of wave and zonal mean processes, J. Climate, 17, 4902-4909, doi:10.1175/JCLI3247.1, 2004.

Perlwitz, J., Pawson, S., Fogt, R. L., Nielsen, J. E., and Neff, W. D.: Impact of stratospheric ozone hole recovery on Antarctic climate, Geophys. Res. Lett., 35, L08714, doi:10.1029/2008GL033317, 2008.

Petropavlovskikh, I., Bhartia, P. K., and DeLuisi, J.: New Umkehr ozone profile retrieval algorithm optimized for climatological studies, Geophys. Res. Lett., 32, L16808, doi:10.1029/2005GL023323, 2005.

Petropavlovskikh, I., Evans, R. D., Carbaugh, G. L., Maillard, E., and Stubi, R.: Towards a Better Knowledge of Umkehr Measurements: A Detailed Study of Data from Thirteen Dobson Intercomparisons (WMO TD No. 1456): WMO Report No 180, 50 pp., December 2008, 2008.

Petropavlovskikh, I., Evans, R. D., McConville, G., Miyagawa, K., and Oltmans, S.: Effect of the out-of-band stray light on the retrieval of the Umkehr Dobson ozone profiles, Int. J. Remote Sens., 30, 6461-6482, 2009.

Poberaj, C. S., Staehelin, J., and Brunner, D.: Missing Stratospheric Ozone Decrease at Southern Hemisphere Middle Latitudes after Mt. Pinatubo: A Dynamical Perspective, J. Atmos. Sci., 68, 1922-1945, 2011.

Randel, W. J., Wu, F., and Stolarski, R. S.: Changes in column ozone correlated with the stratospheric EP flux, J. Meteorol. Soc. Jpn., 80, 849-862, 2002.

Randel, W. J., Shine, K. P., Austin, J., Barnett, J., Claud, C., Gillett, N. P., Keckhut, P., Langematz, U., Lin, R., Long, C., Mears, C., Miller, A., Nash, J., Seidel,D. J., Thompson, D. W. J., Wu, F., and Yoden, S.: An update of observed stratospheric temperature trends, J. Geophys. Res., 114, D02107, doi:10.1029/2008JD010421, 2009.

Ray, E. A., Moore, F. L., Rosenlof, K. H., Davis, S. M., Boenisch, H., Morgenstern, O., Smale, D., Rozanov, E., Hegglin, M., Pitari, G., Mancini, E., Braesicke, P., Butchart, N., Hardiman, S., Li, F., Shibata, K., and Plummer, D. A.: Evidence for changes in 
stratospheric transport and mixing overi the past three decade based on multiple data sets and tropical leaky pipe analysis, J. Geophys. Res., 115, D21304, doi:10.1029/2010JD014206, 2010.

Reinsel, G. C., Weatherhead, E. C., Tiao, G. C., Miller, A. J., Nagatani, R. M., Wuebbles, D. J., and Flynn, L. E.: On detection of turnaround and recovery in trend for ozone, J. Geophys. Res., 107, ACH 1-1-ACH 1-12, doi:10.1029/2001JD000500, 2002.

Reinsel, G. C., Miller, A. J., Weatherhead, E. C., Flynn, L. E., Nagatani, R., Tiao, G. C., and Wuebbles, D. J.: Trend analysis of total ozone data for turnaround and dynamical contributions, J. Geophys. Res., 110, D16306, doi:10.1029/2004JD004662, 2005.

Rienecker, M. M., Suarez, M. J., Todling, R., Bacmeister, J., Takacs, L., Liu, H.-C., Gu, W., Sienkiewicz, M., Koster, R. D., Gelaro, R., Stajner, I., and Nielsen, J. E.: The GEOS-5 Data Assimilation System - Documentation of Versions 5.0.1, 5.1.0, and 5.2.0, Technical Report Series on Global Modeling and Data Assimilation, NASA/TM-2008-104606, 27, 18-61, http://gmao.gsfc.nasa. gov/pubs/docs/Rienecker369.pdf (last access: December 2008), 2008.

Rienecker, M. M., Suarez, M. J., Gelaro, R., Todling R., Bacmeister, J., Liu, E., Bosilovich, M. G., Schubert, S. D., Takacs, L., and Kim, G.-K.: MERRA: NASA's Modern-Era Retrospective Analysis for Research and Applications, J. Climate, 24, 3624-3648, 2011.

Rigby, M., Prinn, R. G., O’Doherty, S., Montzka, S. A., McCulloch, A., Harth, C. M., Mühle, J., Salameh, P. K., Weiss, R. F., Young, D., Simmonds, P. G., Hall, B. D., Dutton, G. S., Nance, D., Mondeel, D. J., Elkins, J. W., Krummel, P. B., Steele, L. P., and Fraser, P. J.: Re-evaluation of the lifetimes of the major CFCs and $\mathrm{CH}_{3} \mathrm{CCl} 3$ using atmospheric trends, Atmos. Chem. Phys., 13, 2691-2702, doi:10.5194/acp-13-2691-2013, 2013.

Salby, M. L., Titova, E., and Deschamps, L.: Rebound of Antarctic ozone, Geophys. Res. Lett., 38, L09702, doi:10.1029/2011GL047266, 2011.

Salby, M. L., Titova, E. A., and Deschamps, L.: Changes of the Antarctic ozone hole: Controlling mechanisms, seasonal predictability, and evolution, J. Geophys. Res., 117, D10111, doi:10.1029/2011JD016285, 2012.

Sassi, F., Kinnison, D., Boville, B. A., Garcia, R. R., and Roble, R.: Effect of El Niño - Southern Oscillation on the dynamical, thermal, and chemical structure of the middle atmosphere, J. Geophys. Res., 109, D17108, doi:10.1029/2003JD004434, 2004.

Sato, M., Hansen, J. E., McCormick, M. P., and Pollack, J. B.: Stratospheric aerosol optical depth, 1850-1990, J. Geophys. Res., 98, 22987-22994, 1993.

Schoeberl, M. R., Lait, L. R., Newman, P. A., and Rosenfield, J. E.: The structure of the polar vortex, J. Geophys. Res., 97, 78597882, 1992.

Solomon, S.: Stratospheric ozone depletion: A review of concepts and history, Rev. Geophys., 37, 275-316, 1999.

Solomon, S., Garcia, R. R., Rowland, F. S., and Wuebbles, D. J.: On the depletion of Antarctic ozone, Nature, 321, 755-758, 1986.

Solomon, S., Portmann, R. W., Sasaki, T., Hofmann, D. J., and Thompson, D. W. J.: Four decades of ozonesonde measurements over Antarctica, J. Geophys. Res., 110, D21311, doi:10.1029/2005JD005917, 2005.

Son, S.-W., Polvani, L. M., Waugh, D. W., Akiyoshi, H., Garcia, R., Kinnison, D., Pawson, S., Rozanov, E., Shepherd, T. G., and Shibata, K.: The Impact of Stratospheric Ozone Recovery on the
Southern Hemisphere Westerly Jet, Science, 320, 1486-1489, doi:10.1126/science.1155939, 2008.

Son, S.-W., Gerber, E. P., Perlwitz, J., Polvani, L. M., Gillett, N. P., Seo, K.H., Eyring, V., Shepherd, T. G., Waugh, D., Akiyoshi, H., Austin, J., Baumgaertner, A., Bekki, S., Braesicke, P., Brühl, C., Butchart, N., Chipperfield, M. P., Cugnet, D., Dameris, M., Dhomse, S., Frith, S., Garny, H., Garcia, R., Hardiman, S. C., Jöckel, P., Lamarque, J. F., Mancini, E., Marchand, M., Michou, M., Nakamura, T., Morgenstern, O., Pitari, G., Plummer, D. A., Pyle, J., Rozanov, E., Scinocca, J. F., Shibata, K., Smale, D., Teyssèdre, H., Tian, W., and Yamashita, Y.: Impact of stratospheric ozone on Southern Hemisphere circulation change: A multimodel assessment, J. Geophys. Res., 115, D00M07, doi:10.1029/2010JD014271, 2010.

Steinbrecht, W., Claude, H., Köhler, U., and Hoinka, K. P.: Correlations Between Tropopause Height and Total Ozone: Implications for Long-Term Changes, J. Geophys. Res., 103, 19183-19192, 1998.

Steinbrecht W., Claude, H., Schönenborn, F., McDermid, I. S., Leblanc, T., Godin-Beekmann, S., Keckhut, P., Hauchecorne, A., Van Gijsel, J. A. E., Swart, D. P. J., Bodeker, G. E., Parrish, A., Boyd, I. S., Kämpfer, N., Hocke, K., Stolarski, R. S., Frith, S. M., Thomason, L. W., Remsberg, E. E., Von Savigny, C., Rozanov, A., and Burrows, J. P.: Ozone and temperature trends in the upper stratosphere at five stations of the Network for the Detection of Atmospheric Composition Change, Int. J. Remote Sens., 30, 3875-3886, 2009.

Stevermer, A. J., Petropavlovskikh, I. V., DeLuisi, J. J., and Rosen, J. M.: Development of a global stratospheric aerosol climatology: optical properties and applications for UV, J. Geophys. Res., 105, 22763-22776, 2000.

Stiller, G. P., von Clarmann, T., Höpfner, M., Glatthor, N., Grabowski, U., Kellmann, S., Kleinert, A., Linden, A., Milz, M., Reddmann, T., Steck, T., Fischer, H., Funke, B., LópezPuertas, M., and Engel, A.: Global distribution of mean age of stratospheric air from MIPAS SF 6 measurements, Atmos. Chem. Phys., 8, 677-695, doi:10.5194/acp-8-677-2008, 2008.

Stiller, G. P., von Clarmann, T., Haenel, F., Funke, B., Glatthor, N., Grabowski, U., Kellmann, S., Kiefer, M., Linden, A., Lossow, S., and López-Puertas, M.: Observed temporal evolution of global mean age of stratospheric air for the 2002 to 2010 period, Atmos. Chem. Phys., 12, 3311-3331, doi:10.5194/acp-12-33112012, 2012.

Stolarski, R. S., Douglass, A. R., Newman, P. A., Pawson, S., and Schoeberl, M. R.: Relative Contribution of Greenhouse Gases and Ozone-Depleting Substances to Temperature Trends in the Stratosphere: A Chemistry-Climate Model Study, J. Climate, 23, 28-42, 2010.

Taguchi, M.: Observed connection of the stratospheric quasi-biennial oscillation with El Niño-Southern Oscillation in radiosonde data, J. Geophys. Res., 115, D18120, doi:10.1029/2010JD014325, 2010.

Thompson, D. W. J. and Solomon, S.: Interpretation of recent Southern Hemisphere climate change, Science, 296, 895-899, 2002.

Thompson, D. W. J., Baldwin, M. P., and Solomon, S.: StratosphereTroposphere Coupling in the Southern Hemisphere, J. Atmos. Sci., 62, 708-715, 2005. 
Thompson, D. W. J., Solomon, S., Kushner, P. J., England, M. H., Grise, K. M., and Karoly, D. J.: Signatures of the Antarctic ozone hole in Southern Hemisphere surface climate change, Nat. Geosci., 4, 741-749, doi:10.1038/ngeo1296, 2011.

Wang, J., Pawson, S., Tian, B., Yung, Y. L., and Jiang, X.: El NinoSouthern Oscillation in Tropical and Midlatitude Column Ozone, J. Atmos. Sci., 68, 1911-1921, 2011.

Waugh, D. W.: Atmospheric dynamics: The age of stratospheric air, Nat. Geosci., 2, 14-16, doi:10.1038/ngeo397, 2009.

Waugh, D. W. and Hall, T. M.: Age of stratospheric air: Theory, observations, and models, Rev. Geophys., 40, 1010, doi:10.1029/2000RG000101, 2002.

Waugh, D. W., Randel, W. J., Pawson, S., Newman, P. A., and Nash, E. R.: Persistence of the Lower Stratospheric Polar Vortices, J. Geophys. Res, 104, 27191-27201, 1999.

Waugh, D. W., Oman, L., Kawa, S. R., Stolarski, R. S., Pawson, S., Douglass, A. R., Newman, P. A., and Nielsen, J. E.: Impacts of climate change on stratospheric ozone recovery, Geophys. Res. Lett., 3, L03805, doi:10.1029/2008GL036223, 2009.

Weiss, A. K., Staehelin, J., Appenzeller, C., and Harris N.: Chemical and dynamical contributions to ozone profile trends of the Payerne (Switzerland) balloon soundings, J. Geophys. Res., 106, 22685-22694, 2001.

WMO (World Meteorological Organization): Scientific Assessment of Ozone Depletion: 1991, Global Ozone Research and Monitoring Project, Report No. 25, 7.1-7.28, Geneva, Switzerland, 1992.

WMO (World Meteorological Organization): Scientific Assessment of Ozone Depletion: 2006, Global Ozone Research and Monitoring Project, Report No. 50, 572 pp., Geneva, Switzerland, 2007.
WMO (World Meteorological Organization): Scientific Assessment of Ozone Depletion: 2010, Global Ozone Research and Monitoring Project, Report No. 52, 516 pp., Geneva, Switzerland, 2011.

Yang, E.-S., Cunnold, D. M., Salawitch, R. J., McCormick, M. P., Russell III, J., Zawodny, J. M., Oltmans, S., and Newchurch, M. J.: Attribution of recovery in lower-stratospheric ozone, J. Geophys. Res., 111, D17309, doi:10.1029/2005JD006371, 2006.

Yang, E.-S., Cunnold, D. M., Newchurch, M. J., Salawitch, R. J., McCormick, M. P., Russell, J. M., Zawodny, J. M., and Oltmans, S. J.: First stage of Antarctic ozone recovery, J. Geophys. Res.AtmoS., 113, D20308, 10.1029/2007JD009675, 2008.

Yoshimatsu, K., Nagata, K., Sakamoto, N., and Fujimoto, T.: Analytical research of the ozone variation factors over Tsukuba, J. Meteorol. Res., 57, 81-94, 2005.

Yuan, X. and Yonekura, E.: Decadal variability in the Southern Hemisphere, J. Geophys. Res., 116, D19115, doi:10.1029/2011JD015673, 2011.

Zanis, P., Maillard, E., Staehelin, J., Zerefos, C., Kosmidis, E., Tourpali, K., and Wohltmann, I.: On the turnaround of stratospheric ozone trends deduced from the reevaluated Umkehr record of Arosa, Switzerland, J. Geophys. Res., 111, D22307, doi:10.1029/2005JD006886, 2006.

Zerefos, C. S., Bais, A. F., Ziomas, I. C., and Bojkov, R. D.: On the Relative Importance of Quasi-Biennial Oscillation and El Nino/Southern Oscillation in the Revised Dobson Total Ozone Records, J. Geophys. Res., 97, 10135-10144, doi:10.1029/92JD00508, 1992. 